\title{
20
}

\section{Implementing a Thermal Urban Runoff Model (TURM)}

\author{
K.E. Arrington, J.M. Norman, A. Roa-Espinosa and S.J. Ventura
}

An Erosion Control and Stormwater Management Ordinance was recently adopted in Dane County, Wisconsin, U.S.A. The thermal control section of this ordinance is one of the first in the nation designed to control heated runoff from impervious surfaces in order to protect cold water streams. This section of the ordinance applies to most new development projects draining to a cold water stream. Temperature reduction practices are required to reduce the potential thermal impact of such development projects.

In order for the thermal control section of this ordinance to be successfully implemented, developers, engineers and county officials must be able to assess the impact of proposed development projects on stream temperatures. A Thermal Urban RunoffModel (TURM) was developed for this purpose. TURM predicts runoff temperatures and flow rates from both pervious and impervious surfaces using weather and landscape factors. It also predicts the effectiveness of management practices for reducing thermal impact. Wilson et al. (2004) and Roa-Espinosa et al. (2003) validated TURM for predicting runoff temperatures in Dane County during four storms in the summer of 1999 and seven storms in the summer of 2000.

Assumed values of weather variables are required to use TURM to predict the thermal impact of a proposed development project. Weather statistics were collected from several stations and a sensitivity analysis of TURM to each of these variables was done in order to select storm conditions with significant thermal impact potential in Dane County. Selecting the design storm values was a key step in shifting TURM from being a validated model to actually being

Arrington, K., J.M. Norman, A. Roa-Espinosa and S.J. Ventura. 2004. "Implementing a Thermal Urban Runoff Model (TURM)." Journal of Water Management Modeling R220-20. doi: 10.14796/JWMM.R220-20.

(c) CHI 2004 www.chijournal.org ISSN: 2292-6062 (Formerly in Innovative Modeling of Urban Water Systems. ISBN: 0-9683681-9-0) 
applied as a predictive tool. Although TURM is currently being used in the Dane County stormwater permitting process, further development of the model has the potential to make TURM a more general planning tool.

\subsection{Introduction}

\subsubsection{Thermal Impact of Urbanization on Cold Water Streams}

The impact of urbanization on stream temperature has been recognized for some time. Although solar radiation and air temperature fluctuations cause water temperature fluctuations in undisturbed streams, streams in urbanized watersheds generally tend to show increased diurnal and seasonal stream temperature fluctuations (Pluhowski, 1970 and Klein, 1979). Several factors associated with urbanization, including the removal of riparian vegetation, the widening of stream channels, the reduction in groundwater inflow to streams and heated runoff from impervious surfaces, have been shown to increase stream temperatures.

The presence of riparian vegetation controls stream temperature fluctuations by reducing the short-wave radiation received by streams during the day and reducing the loss of long-wave radiation from streams to the atmosphere at night (LeBlanc et al., 1996). Therefore, when riparian vegetation is removed in urbanizing watersheds, streams experience greater radiative gains and losses, leading to increased temperature fluctuations. Surface area also affects the energy balance of a stream because most energy exchanges occur at the airwater interface (LeBlanc et al., 1996). Therefore, as streams widen from the streambank erosion caused by increased runoff in urbanized watersheds (Klein, 1979), they experience increased temperature fluctuations. Finally, the presence of impervious surfaces in urban watersheds reduces infiltration leading to decreases in the volume of groundwater contributing to stream flow. This decreases overall baseflow (stream flow during dry periods), which means that less energy is required to raise or lower the stream's temperature, making it more vulnerable to temperature fluctuations. Also, since groundwater is insulated from air temperatures, it typically has the effect of moderating stream temperature fluctuations. Decreased groundwater flow to streams reduces this moderating effect.

The factors described above simply make a stream more exposed to forces that naturally cause temperature fluctuations. The impervious surfaces that are characteristic of urbanized watersheds have been recognized as playing 
applied as a predictive tool. Although TURM is currentlybeing used in the Dane County stormwater permitting process, further development of the model has the potential to make TURM a more general planning tool.

\subsection{Introduction}

\subsubsection{Thermal Impact of Urbanization on Cold Water Streams}

The impact of urbanization on stream temperature has been recognized for some time. Although solar radiation and air temperature fluctuations cause water temperature fluctuations in undisturbed streams, streams in urbanized watersheds generally tend to show increased diurnal and seasonal stream temperature fluctuations (Pluhowski, 1970 and Klein, 1979). Several factors associated with urbanization, including the removal of riparian vegetation, the widening of stream channels, the reduction in groundwater inflow to streams and heated runoff from impervious surfaces, have been shown to increase stream temperatures.

The presence of riparian vegetation controls stream temperature fluctuations by reducing the short-wave radiation received by streams during the day and reducing the loss of long-wave radiation from streams to the atmosphere at night (LeBlanc et al., 1996). Therefore, when riparian vegetation is removed in urbanizing watersheds, streams experience greater radiative gains and losses, leading to increased temperature fluctuations. Surface area also affects the energy balance of a stream because most energy exchanges occur at the airwater interface (LeBlanc et al., 1996). Therefore, as streams widen from the streambank erosion caused by increased runoff in urbanized watersheds (Klein, 1979), they experience increased temperature fluctuations. Finally, the presence of impervious surfaces in urban watersheds reduces infiltration leading to decreases in the volume of groundwater contributing to stream flow. This decreases overall baseflow (stream flow during dry periods), which means that less energy is required to raise or lower the stream's temperature, making it more vulnerable to temperature fluctuations. Also, since groundwater is insulated from air temperatures, it typically has the effect of moderating stream temperature fluctuations. Decreased groundwater flow to streams reduces this moderating effect.

The factors described above simply make a stream more exposed to forces that naturally cause temperature fluctuations. The impervious surfaces that are characteristic of urbanized watersheds have been recognized as playing 
an active role in stream temperature fluctuations. Impervious surfaces are typically better absorbers of solar radiation than natural surfaces, so they usually are warmer, especially during the summer months. Summer afternoon thunderstorms can cause a direct thermal loading on urban streams because the impervious surfaces transfer some of their heat to the precipitation falling on them. This heated water then moves quickly over the impervious surfaces and through storm sewers to nearby streams, giving it little chance to cool. Johnson (1995) and Roa-Espinosa et al. (2003) both noted the impact of heated runoff from impervious surfaces on stream temperature in urban watersheds.

The thermal impact of urbanization on the aquatic life in a stream depends on the extent of urbanization and on the temperatures characteristic of that stream in an undisturbed state. Galli (1990) divides streams into the following three categories based on their maximum summer temperatures: cold water $\left(<21^{\circ} \mathrm{C}\right)$, cool water $\left(\sim 27^{\circ} \mathrm{C}\right)$ and warm water $\left(33-35^{\circ} \mathrm{C}\right)$. Since stream temperatures tend to increase in the downstream direction, differences in aquatic ecosystems can be expected at different locations along a stream's length (Galli, 1990). Cold water streams are typically headwater streams, while the downstream stretches of streams are usually classified as cool water or warm water. As mentioned earlier, streams with smaller discharge rates (headwater streams) are more sensitive to temperature fluctuations. Cold water fish species (often found in headwater streams) also tend to have narrower temperature tolerance ranges than their cool and warm water counterparts (Galli, 1990). Therefore, the thermal impact of urbanization tends to be greatest in small, headwater streams.

\subsubsection{Study Area and Context}

Dane County is a $3207 \mathrm{~km}^{2}$ area (U.S Bureau of the Census, 2003) located in south-central Wisconsin, U.S.A. The county is home to approximately $450 \mathrm{~km}$ of cold water streams (as designated by the Wisconsin Department of Natural Resources). Most of these streams are located among the steeper topography of the western half of the county. Madison, a city of 208,054 people (U.S. Bureau of the Census, 2003), lies in the center of Dane County. The county population increased $14 \%$ (from 367,085 to 426,526 ) between 1990 and 2000 (U.S Bureau of the Census, 2003). Such rapid growth is creating development pressure in many areas that drain to cold water streams.

In an attempt to protect the numerous cold water streams in Dane County from the thermal impact of urbanization, the county board included a thermal control section in the recently adopted Erosion Control and Stormwater 
an active role in stream temperature fluctuations. Impervious surfaces are typically better absorbers of solar radiation than natural surfaces, so they usually are warmer, especially during the summer months. Summer afternoon thunderstorms can cause a direct thermal loading on urban streams because the impervious surfaces transfer some of their heat to the precipitation falling on them. This heated water then moves quickly over the impervious surfaces and through storm sewers to nearby streams, giving it little chance to cool. Johnson (1995) and Roa-Espinosa et al. (2003) both noted the impact of heated runoff from impervious surfaces on stream temperature in urban watersheds.

The thermal impact of urbanization on the aquatic life in a stream depends on the extent of urbanization and on the temperatures characteristic of that stream in an undisturbed state. Galli (1990) divides streams into the following three categories based on their maximum summer temperatures: cold water $\left(<21^{\circ} \mathrm{C}\right)$, cool water $\left(\sim 27^{\circ} \mathrm{C}\right)$ and warm water $\left(33-35^{\circ} \mathrm{C}\right)$. Since stream temperatures tend to increase in the downstream direction, differences in aquatic ecosystems can be expected at different locations along a stream's length (Galli, 1990). Cold water streams are typically headwater streams, while the downstream stretches of streams are usually classified as cool water or warm water. As mentioned earlier, streams with smaller discharge rates (headwater streams) are more sensitive to temperature fluctuations. Cold water fish species (often found in headwater streams) also tend to have narrower temperature tolerance ranges than their cool and warm water counterparts (Galli, 1990). Therefore, the thermal impact of urbanization tends to be greatest in small, headwater streams.

\subsubsection{Study Area and Context}

Dane County is a $3207 \mathrm{~km}^{2}$ area (U.S Bureau of the Census, 2003) located in south-central Wisconsin, U.S.A. The county is home to approximately $450 \mathrm{~km}$ of cold water streams (as designated by the Wisconsin Department of Natural Resources). Most of these streams are located among the steeper topography of the western half of the county. Madison, a city of 208,054 people (U.S. Bureau of the Census, 2003), lies in the center of Dane County. The county population increased $14 \%$ (from 367,085 to 426,526) between 1990 and 2000 (U.S Bureau of the Census, 2003). Such rapid growth is creating development pressure in many areas that drain to cold water streams.

In an attempt to protect the numerous cold water streams in Dane County from the thermal impact of urbanization, the county board included a thermal control section in the recently adopted Erosion Control and Stormwater 
Manangement Ordinance. This section of the ordinance states that stormwater management plans are required to include thermal control practices for all sites that drain to a Cold Water Community (as defined in Wisconsin Administrative Code NR 102.04(3)(a)), unless a county-approved model demonstrates that the post-development runoff temperature increases will be zero. In addition to the modeling effort described herein, other activities to support the ordinance are described in Arrington (2003) and Arrington et al. (2003), including the delineation of cold water watersheds from a digital elevation model and the development of a web-based "locator tool" for determining if a proposed development site is affected by the thermal control section of the ordinance.

A Thermal Urban Runoff Model (TURM) was developed and tested in Dane County specifically for the purpose of assessing the potential thermal impact of development projects and the effectiveness of management practices for reducing that impact. Roa-Espinosa et al. (2003) and Wilson et al. (2004) compared measured runoff temperatures to TURM-predicted runoff temperatures for an urban subwatershed in Dane County during seven storms in the summer of 2000. Results showed that TURM was generally able to predict runoff temperatures within approximately $1-2^{\circ} \mathrm{C}$. TURM was also tested using an independent dataset of weather variables, pavement temperatures and runoff temperatures in Dane County (collected by the Wisconsin Department of Natural Resources in 1999). For this dataset, TURM predicted runoff temperatures within $0.7^{\circ} \mathrm{C}$ of the measured runoff temperatures (Wilson et al., 2004). Based on these two sets of results, the Dane County Land Conservation Department has approved the use of TURM for developing stormwater management plans to comply with the ordinance.

In order to use TURM as a predictive tool, assumptions must be made for all the weather inputs that the model requires. The goal of this project was to select a set of weather conditions to assume for TURM in the Dane County stormwater permitting process. This set of weather conditions is referred to as a "design storm" for TURM, even though the term "design storm" has a much less precise definition than design storms used to predict runoff volumes and flow rates. For example, the 2-y, 24-h design storm for rainfall depth in Dane County is $72 \mathrm{~mm}$, which means that $72 \mathrm{~mm}$ of rain will fall in a $24-\mathrm{h}$ period statistically every $2 \mathrm{y}$ in Dane County. Because TURM uses a number of weather variables to predict runoff temperature, determining a set of storm conditions that will occur statistically every $2 \mathrm{y}$ in Dane County is more complicated. In addition, the "design storm" would need to be a storm that would result in a certain level of thermal impact to cold water streams in Dane County. Since different development projects draining to different cold water 
Manangement Ordinance. This section of the ordinance states that stormwater management plans are required to include thermal control practices for all sites that drain to a Cold Water Community (as defined in Wisconsin Administrative Code NR 102.04(3)(a)), unless a county-approved model demonstrates that the post-development runoff temperature increases will be zero. In addition to the modeling effort described herein, other activities to support the ordinance are described in Arrington (2003) and Arrington et al. (2003), including the delineation of cold water watersheds from a digital elevation model and the development of a web-based "locator tool" for determining if a proposed development site is affected by the thermal control section of the ordinance.

A Thermal Urban Runoff Model (TURM) was developed and tested in Dane County specifically for the purpose of assessing the potential thermal impact of development projects and the effectiveness of management practices for reducing that impact. Roa-Espinosa et al. (2003) and Wilson et al. (2004) compared measured runoff temperatures to TURM-predicted runoff temperatures for an urban subwatershed in Dane County during seven storms in the summer of 2000. Results showed that TURM was generally able to predict runoff temperatures within approximately $1-2^{\circ} \mathrm{C}$. TURM was also tested using an independent dataset of weather variables, pavement temperatures and runoff temperatures in Dane County (collected by the Wisconsin Department of Natural Resources in 1999). For this dataset, TURM predicted runoff temperatures within $0.7^{\circ} \mathrm{C}$ of the measured runoff temperatures (Wilson et al., 2004). Based on these two sets of results, the Dane County Land Conservation Department has approved the use of TURM for developing stormwater management plans to comply with the ordinance.

In order to use TURM as a predictive tool, assumptions must be made for all the weather inputs that the model requires. The goal of this project was to select a set of weather conditions to assume for TURM in the Dane County stormwater permitting process. This set of weather conditions is referred to as a "design storm" for TURM, even though the term "design storm" has a much less precise definition than design storms used to predict runoff volumes and flow rates. For example, the 2-y, 24-h design storm for rainfall depth in Dane County is $72 \mathrm{~mm}$, which means that $72 \mathrm{~mm}$ of rain will fall in a 24-h period statistically every $2 \mathrm{y}$ in Dane County. Because TURM uses a number of weather variables to predict runoff temperature, determining a set of storm conditions that will occur statistically every $2 \mathrm{y}$ in Dane County is more complicated. In addition, the "design storm" would need to be a storm that would result in a certain level of thermal impact to cold water streams in Dane County. Since different development projects draining to different cold water 
streams can have different thermal impacts even under the same set of storm conditions, defining the thermal impact that is appropriate for a design storm is also difficult. Therefore, the design storm conditions presented here were determined from weather statistics for July afternoons, the times of day and year when storms in Dane County have been shown to produce the highest runoff temperatures in urban areas in Dane County (Roa-Espinosa et al., 2003).

\subsection{Background}

TURM is a simple analytical model that operates within a spreadsheet. Two major assumptions were made in order to develop an analytical model so that TURM would be accessible to developers, planners and county officials. TURM assumes that pavement behaves as a semi-infinite conducting media, which allows for the use of the analytical solution for transient conduction from pavement in response to a step change in boundary temperature (Wilson et al., 2004). The other major assumption of the model is that at each point along the pavement slope, conduction from pavement to runoff operates independently of all other points along the slope. This assumption makes it possible to calculate the total heat accumulated in runoff from a section of pavement by integrating the heat that is transferred to the water at each independent point along the pavement's slope (Wilson et al., 2004).

TURM assumes that runoff from impervious surfaces begins immediately, while runoff from impervious surfaces does not begin until the time of concentration. The time of concentration is defined by USDA-SCS (1986) as the length of time that it takes runoff to travel from the hydrologically most distant point in a watershed to a point of interest. In the case of an individual parcel, the time of concentration can be thought of as the time it would take water to travel over the longest possible path to the parcel's outlet (or the time that it would take for the entire parcel to be contributing runoff to its outlet.) The time of concentration for a parcel is a function of the slopes and types of land cover present on the parcel.

TURM predicts runoff temperatures for each time increment during a storm (Roa-Espinosa et al., 2003, and Wilson et al. (2004) used 5-min time increments in the validation study). If detailed rainfall data are available, this information can be used to model runoff temperature fluctuations resulting from intermittent rainfall conditions. Wilson et al. (2004) used 5-min rainfall and runoff averages (collected by the Wisconsin Department of Natural Resources in 1999) and found that TURM was able to capture most runoff 
streams can have different thermal impacts even under the same set of storm conditions, defining the thermal impact that is appropriate for a design storm is also difficult. Therefore, the design storm conditions presented here were determined from weather statistics for July afternoons, the times of day and year when storms in Dane County have been shown to produce the highest runoff temperatures in urban areas in Dane County (Roa-Espinosa et al., 2003).

\subsection{Background}

TURM is a simple analytical model that operates within a spreadsheet. Two major assumptions were made in order to develop an analytical model so that TURM would be accessible to developers, planners and county officials. TURM assumes that pavement behaves as a semi-infinite conducting media, which allows for the use of the analytical solution for transient conduction from pavement in response to a step change in boundary temperature (Wilson et al., 2004). The other major assumption of the model is that at each point along the pavement slope, conduction from pavement to runoff operates independently of all other points along the slope. This assumption makes it possible to calculate the total heat accumulated in runoff from a section of pavement by integrating the heat that is transferred to the water at each independent point along the pavement's slope (Wilson et al., 2004).

TURM assumes that runoff from impervious surfaces begins immediately, while runoff from impervious surfaces does not begin until the time of concentration. The time of concentration is defined by USDA-SCS (1986) as the length of time that it takes runoff to travel from the hydrologically most distant point in a watershed to a point of interest. In the case of an individual parcel, the time of concentration can be thought of as the time it would take water to travel over the longest possible path to the parcel's outlet (or the time that it would take for the entire parcel to be contributing runoff to its outlet.) The time of concentration for a parcel is a function of the slopes and types of land cover present on the parcel.

TURM predicts runoff temperatures for each time increment during a storm (Roa-Espinosa et al., 2003, and Wilson et al. (2004) used 5-min time increments in the validation study). If detailed rainfall data are available, this information can be used to model runoff temperature fluctuations resulting from intermittent rainfall conditions. Wilson et al. (2004) used 5-min rainfall and runoff averages (collected by the Wisconsin Department of Natural Resources in 1999) and found that TURM was able to capture most runoff 
temperature fluctuations during four storms with intermittent rainfall conditions (predicted temperatures were within $0.7^{\circ} \mathrm{C}$ of measured temperatures at each time increment). If detailed rainfall data are not available, rainfall intensity is assumed to be constant over a storm's duration. This assumption is likely to be used often for planning purposes, since it reduces the amount of information required to run the model. Roa-Espinosa et al. (2003) noted that the constant-intensity assumption limited the model's ability to predict fluctuations in runoff temperatures throughout a storm. Despite this assumption, Wilson et al. (2004) noted that for the seven storms studied in the summer of 2000, TURM-predicted runoff temperatures at each time increment were within $2.5^{\circ} \mathrm{C}$ of measured runoff temperatures and that the average difference between predicted and measured runoff temperatures was less than $1^{\circ} \mathrm{C}$.

The current version of TURM assumes that runoff depth is a fixed proportion of rainfall depth. (For pervious surfaces, that proportion is assumed to be 0.4 and for impervious surfaces, it is assumed to be 0.8.) Although RoaEspinosa et al. (2003) and Wilson et al. (2004) found that using this assumption, TURM was able to predict runoff temperatures within $2.5^{\circ} \mathrm{C}$ of measured runoff temperatures for the sites and storms that were included in the validation study, this does not mean that it is an appropriate assumption under all conditions. The amount of precipitation measured on the days that were part of the validation study ranged from 15 to $62 \mathrm{~mm}$ (Wilson et al., 2004). Since the 2-y, 24-h storm in Dane County in $74 \mathrm{~mm}$, the effect of the fixed proportion runoff assumption on TURM's accuracy during large storms in Dane County has not yet been assessed. Also, most of the pervious surfaces in the validation study were residential lawns, so the accuracy of the fixed proportion runoff assumption has not been tested for a wide variety of pervious surfaces. RoaEspinosa et al. (2003) acknowledge that TURM is still in the early stages of development and do not suggest that the model is ready to be applied to a wide variety of conditions without further validation and calibration. Because of these limitations, TURM is currently only being used as a tool to estimate the thermal impact of development projects in Dane County.

TURM requires a number of weather variables that can be grouped into the categories: daily variables (maximum and minimum daily air temperature and maximum daily solar radiation), hourly variables (air temperature and relative humidity prior to the storm and wind speed and solar radiation during the storm) and storm factors (starting hour of the storm, rainfall depth and duration, and rain temperature). These variables are commonly measured at weather stations, with the exception of rain temperature. If measured rain temperatures are not available, rain temperature can be assumed to be equal to 
temperature fluctuations during four storms with intermittent rainfall conditions (predicted temperatures were within $0.7^{\circ} \mathrm{C}$ of measured temperatures at each time increment). If detailed rainfall data are not available, rainfall intensity is assumed to be constant over a storm's duration. This assumption is likely to be used often for planning purposes, since it reduces the amount of information required to run the model. Roa-Espinosa et al. (2003) noted that the constant-intensity assumption limited the model's ability to predict fluctuations in runoff temperatures throughout a storm. Despite this assumption, Wilson et al. (2004) noted that for the seven storms studied in the summer of 2000, TURM-predicted runoff temperatures at each time increment were within $2.5^{\circ} \mathrm{C}$ of measured runoff temperatures and that the average difference between predicted and measured runoff temperatures was less than $1^{\circ} \mathrm{C}$.

The current version of TURM assumes that runoff depth is a fixed proportion of rainfall depth. (For pervious surfaces, that proportion is assumed to be 0.4 and for impervious surfaces, it is assumed to be 0.8.) Although RoaEspinosa et al. (2003) and Wilson et al. (2004) found that using this assumption, TURM was able to predict runoff temperatures within $2.5^{\circ} \mathrm{C}$ of measured runoff temperatures for the sites and storms that were included in the validation study, this does not mean that it is an appropriate assumption under all conditions. The amount of precipitation measured on the days that were part of the validation study ranged from 15 to $62 \mathrm{~mm}$ (Wilson et al., 2004). Since the 2-y, 24-h storm in Dane County in $74 \mathrm{~mm}$, the effect of the fixed proportion runoff assumption on TURM's accuracy during large storms in Dane County has not yet been assessed. Also, most of the pervious surfaces in the validation study were residential lawns, so the accuracy of the fixed proportion runoff assumption has not been tested for a wide variety of pervious surfaces. RoaEspinosa et al. (2003) acknowledge that TURM is still in the early stages of development and do not suggest that the model is ready to be applied to a wide variety of conditions without further validation and calibration. Because of these limitations, TURM is currently only being used as a tool to estimate the thermal impact of development projects in Dane County.

TURM requires a number of weather variables that can be grouped into the categories: daily variables (maximum and minimum daily air temperature and maximum daily solar radiation), hourly variables (air temperature and relative humidity prior to the storm and wind speed and solar radiation during the storm) and storm factors (starting hour of the storm, rainfall depth and duration, and rain temperature). These variables are commonly measured at weather stations, with the exception of rain temperature. If measured rain temperatures are not available, rain temperature can be assumed to be equal to 


\subsection{Background}

the wet bulb temperature at the starting hour of the storm. The wet bulb temperature is the temperature to which air (at a given temperature and vapor pressure) could be cooled by evaporating water into it until it becomes saturated with vapor. The U.S. Army Corps of Engineers (1956) note that wet bulb temperature is generally considered to be a reasonable estimate of rain temperature. Wilson et al. (2004) found that measured rain temperatures were very close to calculated wet bulb temperatures during the storms in the TURM validation study.

A detailed description of TURM can be found in Wilson et al. (2004), but a brief summary of the steps of the model is provided in the list below.

1. Initial impervious surface temperature is predicted for the starting hour of the storm. Impervious surface temperature is assumed to be sinusoidal and is a function of time of day, impervious surface albedo, daily maximum solar radiation, daily maximum and minimum air temperatures and wind speed.

2. Runoff flow rates are predicted separately for impervious and pervious surfaces within the area of analysis. Runoff depths are assumed to be a fixed proportion of rainfall depth. Runoff flows rates for impervious and pervious surfaces are calculated by multiplying the area of each surface by the runoff depth for that surface and dividing by the storm's duration.

3. Runoff temperatures are predicted for impervious surfaces by calculating the energy balance of this water at small time increments throughout the storm. Runoff temperatures from pervious surfaces are assumed to be equal to the rain temperature.

4. The combined temperature of runoff from both surfaces is computed using a flow-weighted average of the temperatures of runoff from the two surfaces at each time increment. The average runoff temperature is calculated by averaging the combined runoff temperature at each time increment over the storm's duration.

5. If temperature reduction practices are used, the average runoff temperature is assumed to be the temperature of the water entering the practice. (A brief description of two temperature reduction practices is provided below.)

6. A flow-weighted average of the runoff temperature (or the temperature exiting a temperature reduction practice if one is used) and stream temperature is used to predict the stream temperature resulting from the storm event. 
the wet bulb temperature at the starting hour of the storm. The wet bulb temperature is the temperature to which air (at a given temperature and vapor pressure) could be cooled by evaporating water into it until it becomes saturated with vapor. The U.S. Army Corps of Engineers (1956) note that wet bulb temperature is generally considered to be a reasonable estimate of rain temperature. Wilson et al. (2004) found that measured rain temperatures were very close to calculated wet bulb temperatures during the storms in the TURM validation study.

A detailed description of TURM can be found in Wilson et al. (2004), but a brief summary of the steps of the model is provided in the list below.

1. Initial impervious surface temperature is predicted for the starting hour of the storm. Impervious surface temperature is assumed to be sinusoidal and is a function of time of day, impervious surface albedo, daily maximum solar radiation, daily maximum and minimum air temperatures and wind speed.

2. Runoff flow rates are predicted separately for impervious and pervious surfaces within the area of analysis. Runoff depths are assumed to be a fixed proportion of rainfall depth. Runoff flows rates for impervious and pervious surfaces are calculated by multiplying the area of each surface by the runoff depth for that surface and dividing by the storm's duration.

3. Runoff temperatures are predicted for impervious surfaces by calculating the energy balance of this water at small time increments throughout the storm. Runoff temperatures from pervious surfaces are assumed to be equal to the rain temperature.

4. The combined temperature of runoff from both surfaces is computed using a flow-weighted average of the temperatures of runoff from the two surfaces at each time increment. The average runoff temperature is calculated by averaging the combined runoff temperature at each time increment over the storm's duration.

5. If temperature reduction practices are used, the average runoff temperature is assumed to be the temperature of the water entering the practice. (A brief description of two temperature reduction practices is provided below.)

6. A flow-weighted average of the runoff temperature (or the temperature exiting a temperature reduction practice if one is used) and stream temperature is used to predict the stream temperature resulting from the storm event. 
Currently TURM includes equations to predict the temperature and flow rate of water exiting two temperature reduction practices: rock cribs and thermal swales. A rock crib is a bed of rocks that receives runoff from a developed area. The purpose of such a structure is to cool heated runoff during its journey to a cold water stream, thereby reducing its thermal impact. This cooling occurs because of heat exchange between hotter water and cooler rocks. The rocks in the crib are kept cooler than the air temperature by being stored (at least partially) underground. A rock crib can also contain groundwater between storm events. During a storm, heated runoff displaces the cool groundwater in the crib, which helps to mitigate the impact of heated runoff on stream temperature. Roa-Espinosa et al. (2003) found that a rock crib at the site of the validation study was able to reduce runoff temperature from impervious areas until the volume of the crib was completely replaced by runoff. After that point, the temperature of water exiting the crib increased because the heated runoff raised the rocks' temperature, reducing their ability to cool additional heated runoff. These findings indicate that the effectiveness of rock cribs is limited by their size and that they should be used in conjunction with other temperature reduction practices.

A thermal swale is a vegetated trench that receives runoff from a developed area. A gentle slope along the bottom of the swale directs runoff toward an outlet pipe, which is at the bottom of one end of the swale. The most important reason why a swale can be an effective structure to reduce thermal impact is that it can reduce the rate of delivery of heated runoff to a stream. If heated runoff is added slowly enough to a cold water stream, it does not raise the stream's temperature significantly because the runoff flow is insignificant relative to the total stream flow. A swale also allows for some reduction in heated runoff volume through infiltration. In addition, although evaporation from a swale is minimal during a storm event, water stored in a swale can lose heat through evaporation after a storm. However, swales must be designed so that they do not store water for more than about $12 \mathrm{~h}$; otherwise they could allow water to regain energy through solar radiation the day after a storm.

Practices other than rock cribs and thermal swales can also be used to reduce the thermal impact of developed areas. Any structure that promotes infiltration, such as an infiltration basin or a rain garden, should reduce thermal impact by increasing baseflow and reducing the volume of heated runoff. Nonstructural practices, such as reducing impervious percentage, disconnecting impervious surfaces or using pavement that absorbs less energy from solar radiation also have the potential for reducing thermal impact. Additional practices should be incorporated into TURM to allow model users to compare 
Currently TURM includes equations to predict the temperature and flow rate of water exiting two temperature reduction practices: rock cribs and thermal swales. A rock crib is a bed of rocks that receives runoff from a developed area. The purpose of such a structure is to cool heated runoff during its journey to a cold water stream, thereby reducing its thermal impact. This cooling occurs because of heat exchange between hotter water and cooler rocks. The rocks in the crib are kept cooler than the air temperature by being stored (at least partially) underground. A rock crib can also contain groundwater between storm events. During a storm, heated runoff displaces the cool groundwater in the crib, which helps to mitigate the impact of heated runoff on stream temperature. Roa-Espinosa et al. (2003) found that a rock crib at the site of the validation study was able to reduce runoff temperature from impervious areas until the volume of the crib was completely replaced by runoff. After that point, the temperature of water exiting the crib increased because the heated runoff raised the rocks' temperature, reducing their ability to cool additional heated runoff. These findings indicate that the effectiveness of rock cribs is limited by their size and that they should be used in conjunction with other temperature reduction practices.

A thermal swale is a vegetated trench that receives runoff from a developed area. A gentle slope along the bottom of the swale directs runoff toward an outlet pipe, which is at the bottom of one end of the swale. The most important reason why a swale can be an effective structure to reduce thermal impact is that it can reduce the rate of delivery of heated runoff to a stream. If heated runoff is added slowly enough to a cold water stream, it does not raise the stream's temperature significantly because the runoff flow is insignificant relative to the total stream flow. A swale also allows for some reduction in heated runoff volume through infiltration. In addition, although evaporation from a swale is minimal during a storm event, water stored in a swale can lose heat through evaporation after a storm. However, swales must be designed so that they do not store water for more than about $12 \mathrm{~h}$; otherwise they could allow water to regain energy through solar radiation the day after a storm.

Practices other than rock cribs and thermal swales can also be used to reduce the thermal impact of developed areas. Any structure that promotes infiltration, such as an infiltration basin or a rain garden, should reduce thermal impact by increasing baseflow and reducing the volume of heated runoff. Nonstructural practices, such as reducing impervious percentage, disconnecting impervious surfaces or using pavement that absorbs less energy from solar radiation also have the potential for reducing thermal impact. Additional practices should be incorporated into TURM to allow model users to compare 
the effectiveness of different practices (or different combinations of practices) when developing stormwater management plans. More extensive testing of the effectiveness of these management practices for reducing thermal impact and TURM's ability to predict that effectiveness is needed before these options can be available to model users however.

\subsection{Methods}

Three tasks were completed prior to selecting the TURM design storm weather values for Dane County. First, weather statistics for several stations in Dane County were collected. Then the range of variation determined from the weather statistics was used to perform a sensitivity analysis of TURM to each of the weather variables it requires. Finally, the weather statistics were compared to values of the weather variables during the storms in the TURM validation study. The sensitivity analysis and the comparison of weather statistics to values measured in the TURM validation study were useful for analyzing the weather statistics before selecting the design storm values.

\subsubsection{Collecting Weather Statistics}

Statistics for all weather variables except rainfall depth and duration were collected from three weather stations. Table 20.1 shows a summary of the years and months collected at each station. Data were only collected from the summer months (May to September) because the potential thermal impact of urbanization is likely to be the greatest at that time of year (Pluhowski, 1970). Daily maximum solar radiation values were only collected for clear days, which were assumed to be days with at least $90 \%$ clear skies. Clear days represent the conditions under which the maximum heating of impervious surfaces occurs and therefore a storm on such days would have a high potential for thermal impact (Roa-Espinosa et al., 2003).

Hourly weather data were collected only for hours during which a storm would be likely to have the greatest thermal impact. In order to determine the hours for which hourly weather data would be collected, statistics were collected for the time of daily maximum air temperature during the summer months. Figure 20.1 shows the results of these statistics for one of the weather stations (similar trends were found at all three weather stations). Based on these results, hourly weather statistics were collected for 1000-1800 hours (henceforth referred to as midday hours) in order to capture weather conditions during most 
the effectiveness of different practices (or different combinations of practices) when developing stormwater management plans. More extensive testing of the effectiveness of these management practices for reducing thermal impact and TURM's ability to predict that effectiveness is needed before these options can be available to model users however.

\subsection{Methods}

Three tasks were completed prior to selecting the TURM design storm weather values for Dane County. First, weather statistics for several stations in Dane County were collected. Then the range of variation determined from the weather statistics was used to perform a sensitivity analysis of TURM to each of the weather variables it requires. Finally, the weather statistics were compared to values of the weather variables during the storms in the TURM validation study. The sensitivity analysis and the comparison of weather statistics to values measured in the TURM validation study were useful for analyzing the weather statistics before selecting the design storm values.

\subsubsection{Collecting Weather Statistics}

Statistics for all weather variables except rainfall depth and duration were collected from three weather stations. Table 20.1 shows a summary of the years and months collected at each station. Data were only collected from the summer months (May to September) because the potential thermal impact of urbanization is likely to be the greatest at that time of year (Pluhowski, 1970). Daily maximum solar radiation values were only collected for clear days, which were assumed to be days with at least $90 \%$ clear skies. Clear days represent the conditions under which the maximum heating of impervious surfaces occurs and therefore a storm on such days would have a high potential for thermal impact (Roa-Espinosa et al., 2003).

Hourly weather data were collected only for hours during which a storm would be likely to have the greatest thermal impact. In order to determine the hours for which hourly weather data would be collected, statistics were collected for the time of daily maximum air temperature during the summer months. Figure 20.1 shows the results of these statistics for one of the weather stations (similar trends were found at all three weather stations). Based on these results, hourly weather statistics were collected for 1000-1800 hours (henceforth referred to as midday hours) in order to capture weather conditions during most 
Table 20.1 Summary of years and months used for weather statistics.

\begin{tabular}{ccccc}
\hline Station Name & Location & $\begin{array}{c}\text { Years of } \\
\text { Record }\end{array}$ & Months of Record & $\begin{array}{c}\text { Observation } \\
\text { Network }\end{array}$ \\
\hline Arlington ARS & Arlington, WI & $1985-2002$ & May-September & AWON \\
West Madison ARS & Madison, WI & $1992-1997$ & May-September & AWON \\
Dane County & Madison, WI & $2000-2002$ & May-September & AWOS \\
Regional Airport & & & & \\
\hline ARS = Agricultural Research Station & & & \\
AWON = UW Automated Weather Observation Network (maintained by the University o \\
$\begin{array}{c}\text { Wisconsin-Madison Soil Science Department) } \\
\text { AWOS = Automated Weather Observing System (maintained by the Federal Aviation } \\
\text { Administration) }\end{array}$
\end{tabular}

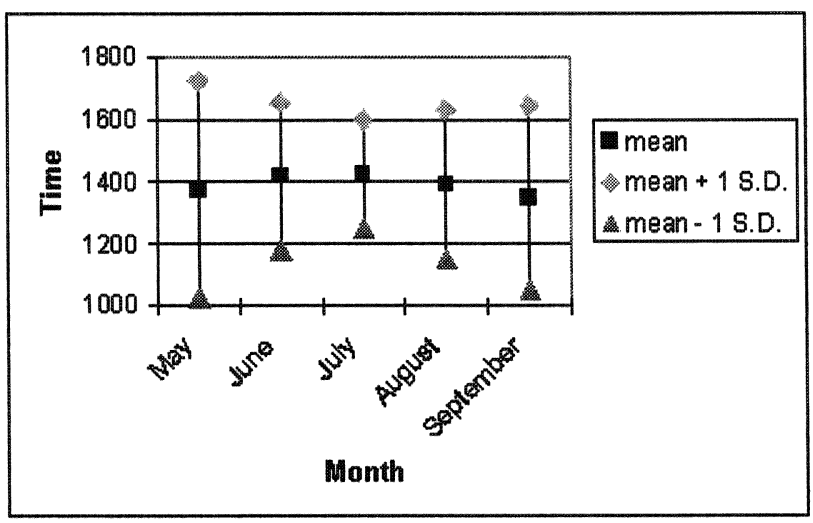

Figure 20.1 Time of maximum air temperature at Arlington weather station (1985-2002).

of the hours that the maximum air temperature would be likely to occur. The hourly solar radiation variable is meant to represent solar radiation during a storm, which can be considerably lower than midday solar radiation on a clear day. Therefore a subset of the midday hours during which precipitation occurred was analyzed to determine the design storm value of solar radiation during the storm.

Statistics for rainfall depth and duration were collected for the storms that were used for the TURM validation study (rather than for storms that occurred at the three weather stations). Storms on seven days during the summer of 2000 were examined in this study. One of these was a small storm that occurred during the early morning hours on June 4, 2000 and produced runoff temperatures that were mostly well below $17^{\circ} \mathrm{C}$ (Roa-Espinosa et al., 2003), 
Table 20.1 Summary of years and months used for weather statistics.

\begin{tabular}{ccccc}
\hline Station Name & Location & $\begin{array}{c}\text { Years of } \\
\text { Record }\end{array}$ & Months of Record & $\begin{array}{c}\text { Observation } \\
\text { Network }\end{array}$ \\
\hline Arlington ARS & Arlington, WI & $1985-2002$ & May-September & AWON \\
West Madison ARS & Madison, WI & $1992-1997$ & May-September & AWON \\
Dane County & Madison, WI & $2000-2002$ & May-September & AWOS \\
Regional Airport & & & & \\
\hline ARS = Agricultural Research Station & & & \\
AWON = UW Automated Weather Observation Network (maintained by the University o \\
$\begin{array}{c}\text { Wisconsin-Madison Soil Science Department) } \\
\text { AWOS = Automated Weather Observing System (maintained by the Federal Aviation } \\
\text { Administration) }\end{array}$
\end{tabular}

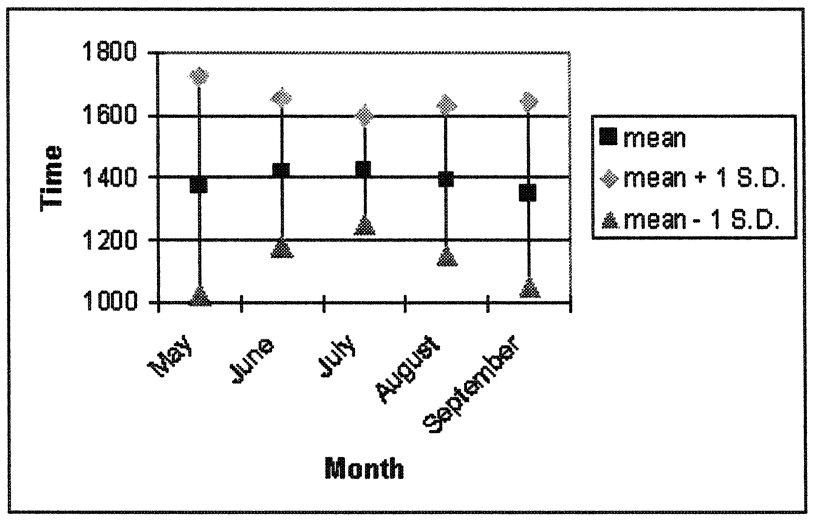

Figure 20.1 Time of maximum air temperature at Arlington weather station (1985-2002).

of the hours that the maximum air temperature would be likely to occur. The hourly solar radiation variable is meant to represent solar radiation during a storm, which can be considerably lower than midday solar radiation on a clear day. Therefore a subset of the midday hours during which precipitation occurred was analyzed to determine the design storm value of solar radiation during the storm.

Statistics for rainfall depth and duration were collected for the storms that were used for the TURM validation study (rather than for storms that occurred at the three weather stations). Storms on seven days during the summer of 2000 were examined in this study. One of these was a small storm that occurred during the early morning hours on June 4, 2000 and produced runoff temperatures that were mostly well below $17^{\circ} \mathrm{C}$ (Roa-Espinosa et al., 2003), 
which is the stream temperature above which some cold water macroinvertebrate species become stressed (Galli, 1990). Because such a storm would have a low potential for thermal impact to a cold water stream, the rainfall depth and duration of this storm was not considered in the statistics for rainfall depth and duration. Although a priori one might not expect the storms in a given summer to be representative of the long term, the average rainfall depth and duration measured during the other six storms in the summer of 2000 turn out to be a good choice for design purposes, as will be discussed later.

During the validation study, precipitation was recorded every $5 \mathrm{~min}$. Because of this small time increment, criteria were needed to determine when a storm on each day began and ended. If any 5-min increment in which no precipitation was measured were considered to be the end of a storm, then there would have been at least several small storms on most of these days. The following criteria were used to determine the rainfall depths and durations for storms during the six selected days of the validation study:

1. precipitation must be measured in at least four consecutive time increments $(20 \mathrm{~min})$ for it to be counted in any storm;

2. no precipitation must occur for at least four consecutive time increments for a storm to be considered over; and

3. at least $2.5 \mathrm{~mm}$ of rain must be measured in any period that satisfies 1 . and 2. for that period to be considered a storm.

Although rain temperatures were measured during the validation study, this is a relatively small sample of rain temperatures, not all of which were collected during the midday hours. Therefore, hourly wet bulb temperature statistics were calculated for the midday hours at the three weather stations in order to determine the range of rain temperatures to test in the sensitivity analysis. Wet bulb temperature is a function of air temperature and vapor pressure, but it cannot be solved for explicitly from relative humidity and air temperature data that was measured; therefore, an iterative approach is required. The details of the method used to calculate the wet bulb temperatures presented here can be found in Arrington (2003).

\subsubsection{Sensitivity Analysis}

Part of the purpose of collecting the weather statistics was to determine a reasonable range of values over which to test each weather variable in the sensitivity analysis. The purpose of the sensitivity analysis itself was to identify the weather variables to which TURM was particularly sensitive. The more sensitive TURM was to a weather variable, the more important it was to 
which is the stream temperature above which some cold water macroinvertebrate species become stressed (Galli, 1990). Because such a storm would have a low potential for thermal impact to a cold water stream, the rainfall depth and duration of this storm was not considered in the statistics for rainfall depth and duration. Although a priori one might not expect the storms in a given summer to be representative of the long term, the average rainfall depth and duration measured during the other six storms in the summer of 2000 turn out to be a good choice for design purposes, as will be discussed later.

During the validation study, precipitation was recorded every $5 \mathrm{~min}$. Because of this small time increment, criteria were needed to determine when a storm on each day began and ended. If any 5-min increment in which no precipitation was measured were considered to be the end of a storm, then there would have been at least several small storms on most of these days. The following criteria were used to determine the rainfall depths and durations for storms during the six selected days of the validation study:

1. precipitation must be measured in at least four consecutive time increments $(20 \mathrm{~min})$ for it to be counted in any storm;

2. no precipitation must occur for at least four consecutive time increments for a storm to be considered over; and

3. at least $2.5 \mathrm{~mm}$ of rain must be measured in any period that satisfies 1 . and 2. for that period to be considered a storm.

Although rain temperatures were measured during the validation study, this is a relatively small sample of rain temperatures, not all of which were collected during the midday hours. Therefore, hourly wet bulb temperature statistics were calculated for the midday hours at the three weather stations in order to determine the range of rain temperatures to test in the sensitivity analysis. Wet bulb temperature is a function of air temperature and vapor pressure, but it cannot be solved for explicitly from relative humidity and air temperature data that was measured; therefore, an iterative approach is required. The details of the method used to calculate the wet bulb temperatures presented here can be found in Arrington (2003).

\subsubsection{Sensitivity Analysis}

Part of the purpose of collecting the weather statistics was to determine a reasonable range of values over which to test each weather variable in the sensitivity analysis. The purpose of the sensitivity analysis itself was to identify the weather variables to which TURM was particularly sensitive. The more sensitive TURM was to a weather variable, the more important it was to 
carefully select a reasonable value of this variable for the design storm. In addition to the weather variables, the sensitivity of TURM to pavement albedo (the fraction of incident solar radiation that is reflected) was analyzed to estimate the predicted effectiveness of using lighter-colored pavement to reduce thermal impact.

To perform the sensitivity analysis for each variable, the value of that variable was varied, while the values of all the other variables were held constant. For each variable analyzed, one run of TURM was done using the mean July value for that variable and two runs were done using the July mean value plus and minus the standard deviation. These three values for each variable were selected to capture the range of variation in runoff temperatures predicted by TURM over the typical range of values expected for each variable during a summer thunderstorm in Dane County. The July weather statistics were used because the conditions during that month consistently had the highest potential for thermal impact at all three weather stations.

A "run" of TURM refers to using TURM to predict average runoff temperature from a given parcel area (a 40.5 ha parcel was used for this analysis) and set of weather values for 0 to $100 \%$ imperviousness at $10 \%$ increments. For this analysis, rainfall intensity was assumed to be constant (the total rainfall depth was divided evenly among the 6-min time increments that were used in the sensitivity analysis). Although TURM is not limited to predicting average runoff temperatures and assuming constant rainfall intensity, these assumptions were made to simplify the sensitivity analysis. The time of concentration for the parcel in this analysis was assumed to be $0.41 \mathrm{~h}$ for residential developments (less than $50 \%$ imperviousness) and $0.31 \mathrm{~h}$ for commercial developments (greater than $50 \%$ imperviousness). The calculations for these times of concentration can be found in Arrington (2003).

\subsubsection{Review of the Weather Conditions during the Storms in the TURM Validation Study}

The sensitivity analysis revealed the weather variables to which TURM was most sensitive. However, before selecting the design-storm values, values of weather variables at the three stations were compared to the corresponding values during the storms in the TURM validation study. These data were collected from a weather station in Sun Prairie, Wisconsin from May-August 2000. There were two reasons for this comparison. The first was to verify whether or not the weather statistics collected for all summer days (or only on certain hours during those days) were reasonable to represent the weather 
carefully select a reasonable value of this variable for the design storm. In addition to the weather variables, the sensitivity of TURM to pavement albedo (the fraction of incident solar radiation that is reflected) was analyzed to estimate the predicted effectiveness of using lighter-colored pavement to reduce thermal impact.

To perform the sensitivity analysis for each variable, the value of that variable was varied, while the values of all the other variables were held constant. For each variable analyzed, one run of TURM was done using the mean July value for that variable and two runs were done using the July mean value plus and minus the standard deviation. These three values for each variable were selected to capture the range of variation in runoff temperatures predicted by TURM over the typical range of values expected for each variable during a summer thunderstorm in Dane County. The July weather statistics were used because the conditions during that month consistently had the highest potential for thermal impact at all three weather stations.

A "run" of TURM refers to using TURM to predict average runoff temperature from a given parcel area (a 40.5 ha parcel was used for this analysis) and set of weather values for 0 to $100 \%$ imperviousness at $10 \%$ increments. For this analysis, rainfall intensity was assumed to be constant (the total rainfall depth was divided evenly among the 6-min time increments that were used in the sensitivity analysis). Although TURM is not limited to predicting average runoff temperatures and assuming constant rainfall intensity, these assumptions were made to simplify the sensitivity analysis. The time of concentration for the parcel in this analysis was assumed to be $0.41 \mathrm{~h}$ for residential developments (less than $50 \%$ imperviousness) and $0.31 \mathrm{~h}$ for commercial developments (greater than $50 \%$ imperviousness). The calculations for these times of concentration can be found in Arrington (2003).

\subsubsection{Review of the Weather Conditions during the Storms in the TURM Validation Study}

The sensitivity analysis revealed the weather variables to which TURM was most sensitive. However, before selecting the design-storm values, values of weather variables at the three stations were compared to the corresponding values during the storms in the TURM validation study. These data were collected from a weather station in Sun Prairie, Wisconsin from May-August 2000. There were two reasons for this comparison. The first was to verify whether or not the weather statistics collected for all summer days (or only on certain hours during those days) were reasonable to represent the weather 
conditions on those days in which a storm occurred. For example, when collecting the maximum solar radiation statistics, only clear days were used. The clear-day maximum solar radiation statistics were compared to the Sun Prairie maximum daily solar radiation statistics on storm days to determine if the maximum solar radiation on a storm day could be assumed to be as high as that of a clear day. The second reason for comparing the Sun Prairie weather data to the other weather data is that the Sun Prairie data were collected in a more urban setting than the other weather stations. (The Arlington station is in a more rural location since it is used for agricultural research. The airport is the most similar to an urban setting of the three weather stations from which data were collected.) Since some development projects for which the prediction of thermal impact will be required will take place in areas that are already urbanized, differences in weather conditions between rural and urban areas should be identified before selecting the design storm values.

\subsubsection{Selecting the Design Storm Values}

Design storm values were selected for each weather variable that TURM requires, using the weather statistics, the sensitivity analysis, and the results of the comparison between the weather statistics and the measured weather conditions at Sun Prairie on storm days. In general, the mean monthly values for July were used since those values usually would result in a design storm with the highest potential for thermal impact. The TURM validation study also showed that July is the month when Dane County storms generally have the greatest potential for thermal impact (Roa-Espinosa et al., 2003). If there was a significant difference among the three stations for the July mean monthly value for a given weather variable, and if TURM was shown to be relatively sensitive to the value of that weather variable, the more conservative value for that weather variable (meaning the value that would result in a storm with a greater thermal impact potential) was selected for the design storm.

\subsection{Results and Discussion}

\subsubsection{Weather Statistics}

The complete weather statistics for all three stations in all months and years analyzed can be found in Arrington (2003). Although some significant differences were found among the three weather stations, for certain weather 
conditions on those days in which a storm occurred. For example, when collecting the maximum solar radiation statistics, only clear days were used. The clear-day maximum solar radiation statistics were compared to the Sun Prairie maximum daily solar radiation statistics on storm days to determine if the maximum solar radiation on a storm day could be assumed to be as high as that of a clear day. The second reason for comparing the Sun Prairie weather data to the other weather data is that the Sun Prairie data were collected in a more urban setting than the other weather stations. (The Arlington station is in a more rural location since it is used for agricultural research. The airport is the most similar to an urban setting of the three weather stations from which data were collected.) Since some development projects for which the prediction of thermal impact will be required will take place in areas that are already urbanized, differences in weather conditions between rural and urban areas should be identified before selecting the design storm values.

\subsubsection{Selecting the Design Storm Values}

Design storm values were selected for each weather variable that TURM requires, using the weather statistics, the sensitivity analysis, and the results of the comparison between the weather statistics and the measured weather conditions at Sun Prairie on storm days. In general, the mean monthly values for July were used since those values usually would result in a design storm with the highest potential for thermal impact. The TURM validation study also showed that July is the month when Dane County storms generally have the greatest potential for thermal impact (Roa-Espinosa et al., 2003). If there was a significant difference among the three stations for the July mean monthly value for a given weather variable, and if TURM was shown to be relatively sensitive to the value of that weather variable, the more conservative value for that weather variable (meaning the value that would result in a storm with a greater thermal impact potential) was selected for the design storm.

\subsection{Results and Discussion}

\subsubsection{Weather Statistics}

The complete weather statistics for all three stations in all months and years analyzed can be found in Arrington (2003). Although some significant differences were found among the three weather stations, for certain weather 
Table 20.2 Precipitation depth and duration for selected Token Creek storms.

\begin{tabular}{ccc}
\hline Date & Duration (h) & Rain (cm) \\
\hline $6 / 1 / 2000$ & 4.83 & 3.64 \\
$6 / 1 / 2000$ & 1.75 & 5.12 \\
$6 / 13 / 2000$ & 6.58 & 4.80 \\
$6 / 20 / 2000$ & 2.75 & 1.71 \\
$7 / 2 / 2000$ & 2.50 & 2.71 \\
$7 / 10 / 2000$ & 4.50 & 2.37 \\
$8 / 5 / 2000$ & 7.58 & 3.35 \\
\hline Mean & 4.36 & 3.39 \\
Standard Deviation & 2.18 & 1.25 \\
\hline
\end{tabular}

variables, the values of these variables were almost always more conservative at Arlington than at either of the other two stations. Therefore, the weather statistics for July at Arlington were used to determine the range of values (mean plus and minus one standard deviation) used for all weather variables in the sensitivity analysis, except for rainfall depth and duration.

Table 20.2 shows a summary of the rainfall data for the other six days used in the TURM validation study. The values used for rainfall depth and duration in the sensitivity analysis are given by the mean values plus and minus one standard deviation as shown in Table 20.2. Although these values are based on only one summer's worth of storms, comparing them with statistics that are based on a longer period of record provides context as to how typical storms of these sizes are in Dane County. The range of values tested for rainfall depth and duration in the sensitivity analysis were $22-46 \mathrm{~mm}$ of rain and $2.1-6.7 \mathrm{~h}$. By comparison the 2-y, 24-h storm for Dane County is $74 \mathrm{~mm}$ and $90 \%$ of the average annual rainfall depth in the Midwestern United States is produced during storms that are equal to or less than $25 \mathrm{~mm}$ (Roesner et al., 1991; Pitt 1991). This indicates that the average rainfall depth and duration $(33 \mathrm{~mm}$ in $4.4 \mathrm{~h}$ ) from the validation study is likely to be larger than most storms in any given year in Dane County, but that a storm of this size is statistically likely to occur more often than every $2 \mathrm{y}$.

\subsubsection{Sensitivity Analysis}

Table 20.3 shows a summary of the weather statistics that were used to run the sensitivity analysis. Figures 20.2-20.12 show the results of the sensitivity analysis. This analysis indicates that TURM is generally less sensitive to the 
Table 20.2 Precipitation depth and duration for selected Token Creek storms.

\begin{tabular}{ccc}
\hline Date & Duration (h) & Rain (cm) \\
\hline $6 / 1 / 2000$ & 4.83 & 3.64 \\
$6 / 1 / 2000$ & 1.75 & 5.12 \\
$6 / 13 / 2000$ & 6.58 & 4.80 \\
$6 / 20 / 2000$ & 2.75 & 1.71 \\
$7 / 2 / 2000$ & 2.50 & 2.71 \\
$7 / 10 / 2000$ & 4.50 & 2.37 \\
$8 / 5 / 2000$ & 7.58 & 3.35 \\
\hline Mean & 4.36 & 3.39 \\
Standard Deviation & 2.18 & 1.25 \\
\hline
\end{tabular}

variables, the values of these variables were almost always more conservative at Arlington than at either of the other two stations. Therefore, the weather statistics for July at Arlington were used to determine the range of values (mean plus and minus one standard deviation) used for all weather variables in the sensitivity analysis, except for rainfall depth and duration.

Table 20.2 shows a summary of the rainfall data for the other six days used in the TURM validation study. The values used for rainfall depth and duration in the sensitivity analysis are given by the mean values plus and minus one standard deviation as shown in Table 20.2. Although these values are based on only one summer's worth of storms, comparing them with statistics that are based on a longer period of record provides context as to how typical storms of these sizes are in Dane County. The range of values tested for rainfall depth and duration in the sensitivity analysis were $22-46 \mathrm{~mm}$ of rain and 2.1-6.7 $\mathrm{h}$. By comparison the 2-y, 24-h storm for Dane County is $74 \mathrm{~mm}$ and $90 \%$ of the average annual rainfall depth in the Midwestern United States is produced during storms that are equal to or less than $25 \mathrm{~mm}$ (Roesner et al., 1991; Pitt 1991). This indicates that the average rainfall depth and duration $(33 \mathrm{~mm}$ in $4.4 \mathrm{~h}$ ) from the validation study is likely to be larger than most storms in any given year in Dane County, but that a storm of this size is statistically likely to occur more often than every $2 \mathrm{y}$.

\subsubsection{Sensitivity Analysis}

Table 20.3 shows a summary of the weather statistics that were used to run the sensitivity analysis. Figures 20.2-20.12 show the results of the sensitivity analysis. This analysis indicates that TURM is generally less sensitive to the 
daily and storm factors compared to the hourly factors. A discussion of why TURM is more sensitive to some variables than others over the range of values tested is presented below. The range of values tested in the sensitivity analysis only represents those values that would be likely to occur on a midsummer afternoon, so the relative sensitivity of TURM to each of the weather variables does not necessarily apply for other times of the day or year.

Table 20.3 Summary of weather variables used for the sensitivity analysis.

\begin{tabular}{|c|c|c|c|}
\hline Weather Variable & Low value & Medium value & High value \\
\hline Maximum daily air temperature $-\mathrm{C}$ & 23 & 27 & 31 \\
\hline Minimum daily air temperature - $\mathrm{C}$ & 12 & 15 & 18 \\
\hline Maximum daily solar radiation - $\mathrm{C}$ & 940 & 970 & 1000 \\
\hline Air temperature just prior to the storm - C & 22 & 26 & 30 \\
\hline Relative humidity just prior to the storm - $\%$ & 40 & 60 & 80 \\
\hline Wind speed during the storm $-\mathrm{m} / \mathrm{s}$ & 2 & 3.5 & 5 \\
\hline Solar radiation during the storm- $\mathrm{W} / \mathrm{m}^{\wedge} 2$ & 50 & 150 & 250 \\
\hline Hour that the storm begins & 10 & 14 & 18 \\
\hline Rainfall depth - mm & 22 & 34 & 46 \\
\hline Rainfall duration - hours & 2.2 & 4.4 & 6.6 \\
\hline Rain temperature - C & 17 & 21.1 & 25 \\
\hline
\end{tabular}

The daily weather variables (maximum and minimum air temperature and maximum solar radiation) are used by TURM to define a sine curve to approximate impervious surface temperature at hourly increments, so these weather variables influence the impervious surface temperature at the starting hour of the storm. The range of maximum air temperatures tested in the sensitivity analysis $\left(23-31^{\circ} \mathrm{C}\right)$ resulted in a similar range of initial impervious surface temperatures $\left(39.8-47.9^{\circ} \mathrm{C}\right)$ and a somewhat smaller range of initial runoff temperatures from impervious surfaces $\left(35.2-40.8^{\circ} \mathrm{C}\right)$. Once the storm begins, the impervious surface temperature is no longer predicted by this sine curve approximation because the rain falling on the impervious surfaces cools them. This cooling causes runoff temperatures to decrease exponentially as the storm progresses. As a result, Figure 20.2 shows that the average predicted runoff temperature over the storm's duration is only moderately affected by daily maximum air temperature. This tends to occur because most storm durations are long enough to extract most of the heat from the pavement; the heat storage being proportional to the initial minus final pavement temperatures, where the final pavement temperature approaches the rainfall temperature. 
daily and storm factors compared to the hourly factors. A discussion of why TURM is more sensitive to some variables than others over the range of values tested is presented below. The range of values tested in the sensitivity analysis only represents those values that would be likely to occur on a midsummer afternoon, so the relative sensitivity of TURM to each of the weather variables does not necessarily apply for other times of the day or year.

Table 20.3 Summary of weather variables used for the sensitivity analysis.

\begin{tabular}{lccc}
\hline Weather Variable & Low value & Medium value & High value \\
\hline Maximum daily air temperature - C & 23 & 27 & 31 \\
Minimum daily air temperature - C & 12 & 15 & 18 \\
Maximum daily solar radiation - C & 940 & 970 & 1000 \\
Air temperature just prior to the storm - C & 22 & 26 & 30 \\
Relative humidity just prior to the storm - \% & 40 & 60 & 80 \\
Wind speed during the storm - $\mathrm{m} / \mathrm{s}$ & 2 & 3.5 & 5 \\
Solar radiation during the storm- W/m^2 & 50 & 150 & 250 \\
Hour that the storm begins & 10 & 14 & 18 \\
Rainfall depth - mm & 22 & 34 & 46 \\
Rainfall duration - hours & 2.2 & 4.4 & 6.6 \\
Rain temperature - C & 17 & 21.1 & 25 \\
\hline
\end{tabular}

The daily weather variables (maximum and minimum air temperature and maximum solar radiation) are used by TURM to define a sine curve to approximate impervious surface temperature at hourly increments, so these weather variables influence the impervious surface temperature at the starting hour of the storm. The range of maximum air temperatures tested in the sensitivity analysis $\left(23-31^{\circ} \mathrm{C}\right)$ resulted in a similar range of initial impervious surface temperatures $\left(39.8-47.9^{\circ} \mathrm{C}\right)$ and a somewhat smaller range of initial runoff temperatures from impervious surfaces $\left(35.2-40.8^{\circ} \mathrm{C}\right)$. Once the storm begins, the impervious surface temperature is no longer predicted by this sine curve approximation because the rain falling on the impervious surfaces cools them. This cooling causes runoff temperatures to decrease exponentially as the storm progresses. As a result, Figure 20.2 shows that the average predicted runoff temperature over the storm's duration is only moderately affected by daily maximum air temperature. This tends to occur because most storm durations are long enough to extract most of the heat from the pavement; the heat storage being proportional to the initial minus final pavement temperatures, where the final pavement temperature approaches the rainfall temperature. 


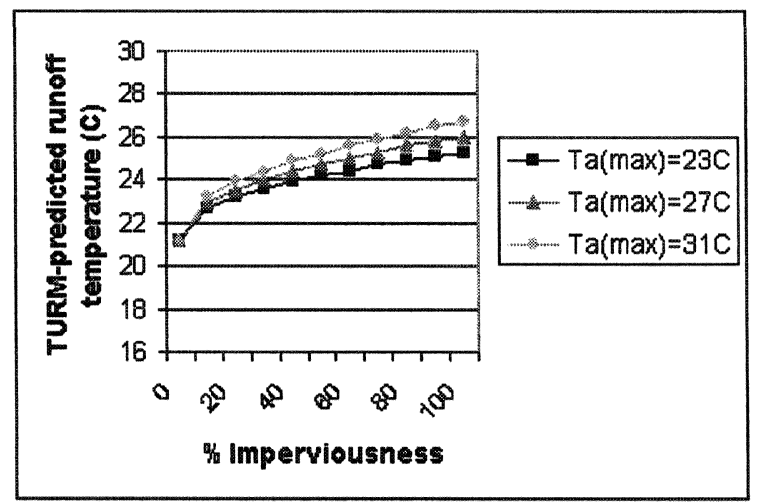

Figure 20.2 Sensitivity of TURM to daily maximum air temperature.

TURM is less sensitive to minimum air temperature than maximum air temperature (results not shown) because this analysis assumed that the storm began in the middle of the day (when the potential for thermal impact is greatest) during which time the impervious surface temperature is unaffected by the minimum air temperature.

TURM appears not to be very sensitive to daily maximum solar radiation over the range of variation in clear day statistics listed in Table 20.3 (results not shown). However, when a wide range of solar radiation input is used (typical of the range of variation between clear and cloudy days), TURM is moderately sensitive to the value of daily maximum solar radiation (Figure 20.3). While the average predicted runoff temperatures shown in Figures 20.2 and 20.3 may obscure the effects of daily maximum air temperature and daily maximum solar radiation on runoff temperatures predicted during the early part of the storm, average predicted runoff temperatures are useful for assessing the model's relative sensitivity to each of its weather variables. TURM is more sensitive to variables that affect runoff temperature throughout the storm than variables that primarily affect runoff temperature early in the storm and the use of average predicted runoff temperatures in the analyses below demonstrates these differences.

Since air temperature, wet bulb temperature and relative humidity are interdependent, only one of these variables can be held constant at a time. Figure 20.4 shows the sensitivity of TURM to air temperature $(\mathrm{Ta})$ by holding relative humidity constant and allowing wet bulb temperature (Tw) to vary accordingly. Increasing air temperature while holding relative humidity constant means that the wet bulb temperature must also increase. Thus the main reason why 


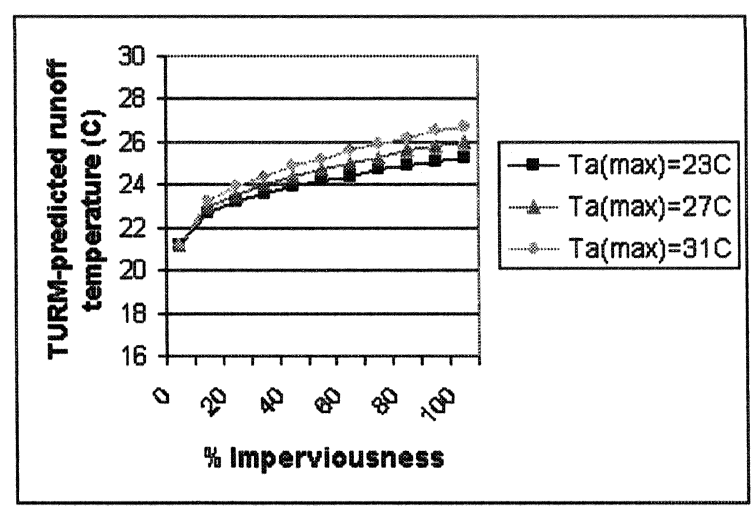

Figure 20.2 Sensitivity of TURM to daily maximum air temperature.

TURM is less sensitive to minimum air temperature than maximum air temperature (results not shown) because this analysis assumed that the storm began in the middle of the day (when the potential for thermal impact is greatest) during which time the impervious surface temperature is unaffected by the minimum air temperature.

TURM appears not to be very sensitive to daily maximum solar radiation over the range of variation in clear day statistics listed in Table 20.3 (results not shown). However, when a wide range of solar radiation input is used (typical of the range of variation between clear and cloudy days), TURM is moderately sensitive to the value of daily maximum solar radiation (Figure 20.3). While the average predicted runoff temperatures shown in Figures 20.2 and 20.3 may obscure the effects of daily maximum air temperature and daily maximum solar radiation on runoff temperatures predicted during the early part of the storm, average predicted runoff temperatures are useful for assessing the model's relative sensitivity to each of its weather variables. TURM is more sensitive to variables that affect runoff temperature throughout the storm than variables that primarily affect runoff temperature early in the storm and the use of average predicted runoff temperatures in the analyses below demonstrates these differences.

Since air temperature, wet bulb temperature and relative humidity are interdependent, only one of these variables can be held constant at a time. Figure 20.4 shows the sensitivity of TURM to air temperature $(\mathrm{Ta})$ by holding relative humidity constant and allowing wet bulb temperature (Tw) to vary accordingly. Increasing air temperature while holding relative humidity constant means that the wet bulb temperature must also increase. Thus the main reason why 


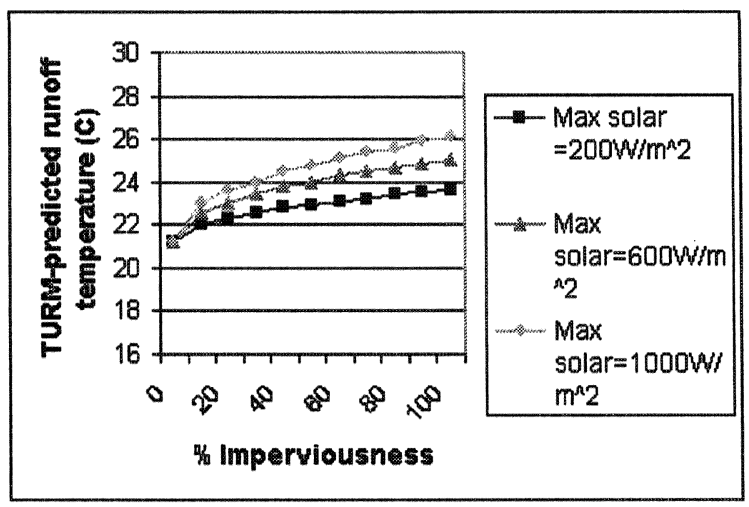

Figure 20.3 Sensitivity of TURM to daily maximum solar radiation.

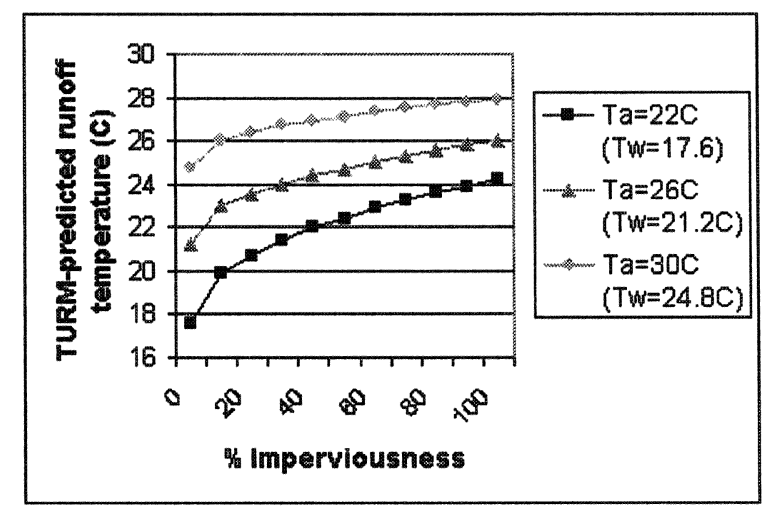

Figure 20.4 Sensitivity of TURM to air temperature prior to the storm.

predicted runoff temperature increases with increasing air temperature in Figure 20.4, regardless of the impervious percentage, is that rain temperature increases with increasing air temperature when relative humidity is held constant. This suggests that runoff temperature can vary significantly even in undeveloped watersheds, simply because of the variability of air and rain temperatures. Data collected in the TURM validation study support this prediction. During the summer of 2000 , rain temperatures collected ranged from $9-22^{\circ} \mathrm{C}$. In one undeveloped area that was included in the study, runoff 


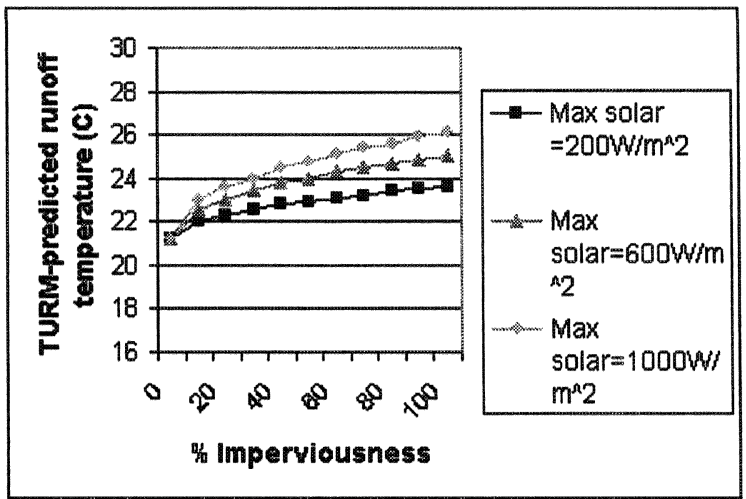

Figure 20.3 Sensitivity of TURM to daily maximum solar radiation.

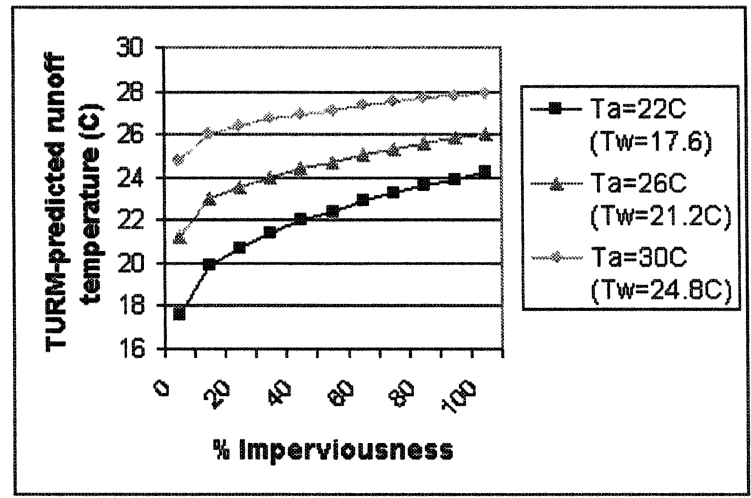

Figure 20.4 Sensitivity of TURM to air temperature prior to the storm.

predicted runoff temperature increases with increasing air temperature in Figure 20.4, regardless of the impervious percentage, is that rain temperature increases with increasing air temperature when relative humidity is held constant. This suggests that runoff temperature can vary significantly even in undeveloped watersheds, simply because of the variability of air and rain temperatures. Data collected in the TURM validation study support this prediction. During the summer of 2000 , rain temperatures collected ranged from $9-22^{\circ} \mathrm{C}$. In one undeveloped area that was included in the study, runoff 


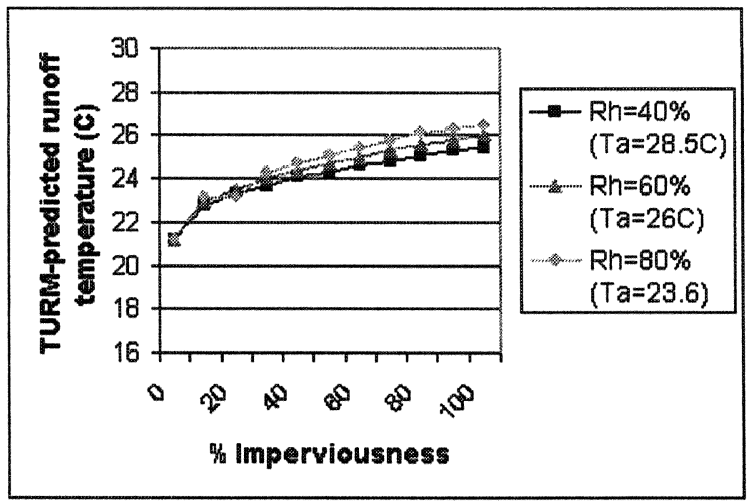

Figure 20.5 Sensitivity of TURM to relative humidity prior to the storm.

temperatures on June 4, 2000 measured approximately $13-14^{\circ} \mathrm{C}$, while on July 10,2000 runoff temperatures ranged from $16-22^{\circ} \mathrm{C}$ (Roa-Espinosa et al., 2003). The mean air and rain temperatures measured were $12.7^{\circ} \mathrm{C}$ and $12.1^{\circ} \mathrm{C}$ on June 4 and $20.9^{\circ} \mathrm{C}$ and $20.6^{\circ} \mathrm{C}$ on July 10 (Wilson et al., 2004).

Figure 20.5 shows the effect of varying relative humidity $(\mathrm{Rh})$ while holding the wet bulb temperature constant. In order for relative humidity to increase at constant wet bulb temperature, air temperature must decrease. Likewise, at constant wet bulb temperature, if relative humidity decreases then air temperature must increase. Relative humidity refers to the conditions just prior to the storm since TURM accounts for the fact that once a storm begins, relative humidity increases to close to $100 \%$. Figure 20.5 indicates that higher relative humidity produces slightly higher predicted runoff temperatures because runoff that has been heated through contact with impervious surfaces is less able to cool through evaporation at higher relative humidity. Because relative humidity approaches $100 \%$ shortly after the storm begins, initial relative humidity has little effect on the average predicted runoff temperature over the storm's duration.

Although Figure 20.4 shows that runoff temperature increases with increasing air temperature, Figure 20.5 shows a lower air temperature results in a higher runoff temperature. The reason for this is that in Figure 20.4, increasing air temperature caused the rain (wet bulb) temperature to increase (since relative humidity was held constant), while in Figure 20.5 the rain (wet bulb) temperature was held constant while air temperature and relative humidity were varied. The fact that Figure 20.5 shows slightly higher predicted runoff 


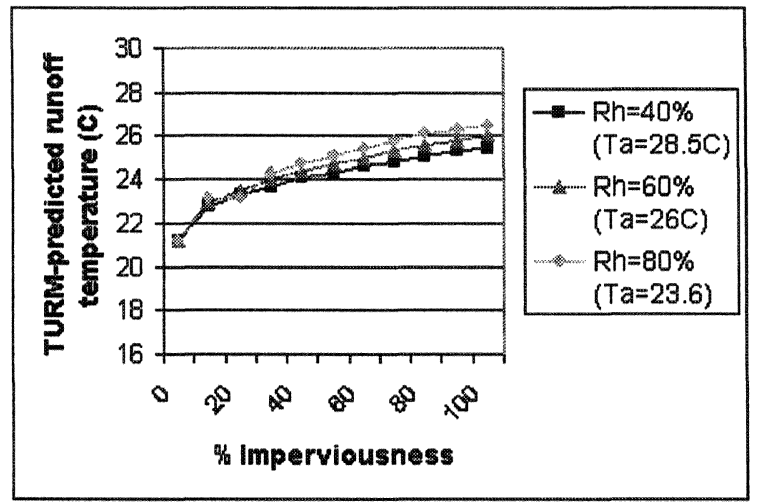

Figure 20.5 Sensitivity of TURM to relative humidity prior to the storm.

temperatures on June 4, 2000 measured approximately $13-14^{\circ} \mathrm{C}$, while on July 10,2000 runoff temperatures ranged from $16-22^{\circ} \mathrm{C}$ (Roa-Espinosa et al., 2003). The mean air and rain temperatures measured were $12.7^{\circ} \mathrm{C}$ and $12.1^{\circ} \mathrm{C}$ on June 4 and $20.9^{\circ} \mathrm{C}$ and $20.6^{\circ} \mathrm{C}$ on July 10 (Wilson et al., 2004).

Figure 20.5 shows the effect of varying relative humidity $(\mathrm{Rh})$ while holding the wet bulb temperature constant. In order for relative humidity to increase at constant wet bulb temperature, air temperature must decrease. Likewise, at constant wet bulb temperature, if relative humidity decreases then air temperature must increase. Relative humidity refers to the conditions just prior to the storm since TURM accounts for the fact that once a storm begins, relative humidity increases to close to $100 \%$. Figure 20.5 indicates that higher relative humidity produces slightly higher predicted runoff temperatures because runoff that has been heated through contact with impervious surfaces is less able to cool through evaporation at higher relative humidity. Because relative humidity approaches $100 \%$ shortly after the storm begins, initial relative humidity has little effect on the average predicted runoff temperature over the storm's duration.

Although Figure 20.4 shows that runoff temperature increases with increasing air temperature, Figure 20.5 shows a lower air temperature results in a higher runoff temperature. The reason for this is that in Figure 20.4, increasing air temperature caused the rain (wet bulb) temperature to increase (since relative humidity was held constant), while in Figure 20.5 the rain (wet bulb) temperature was held constant while air temperature and relative humidity were varied. The fact that Figure 20.5 shows slightly higher predicted runoff 
temperatures at lower air temperatures is an indication that TURM-predicted runoff temperatures are sensitive to rain temperature more than they are to air temperature. Although the highest runoff temperatures will generally be measured on the warmest days, this analysis indicates that this is not so much because warm air directly warms water after it begins to run off, but rather that warm air leads to warmer rain, even before that rain contacts the earth's surface.

Figure 20.6 shows that runoff temperatures predicted by TURM are also sensitive to wind speed during the storm. Higher wind speeds allow for more cooling of the heated runoff from impervious surfaces because of increased surface transfer coefficients. Because the pavement surface is warmer than the air, evaporation occurs from this wet surface even though the air is nearly saturated, and a higher transfer coefficient results in more evaporative cooling. Often this rapid evaporation into the nearly saturated air results in condensation or steam fog forming when cool rain falls on hot pavement. A higher transfer coefficient also results in more cooling by sensible heat transfer. Wind speed also affects the initial impervious surface temperature; higher wind speeds cause lower impervious surface temperature because of increased convective heat transfer away from the pavement. Larger changes in initial impervious surface temperature were found over the range of values tested for midday hourly wind speed than for daily solar maximum radiation or maximum air temperature. Thus, when wind speed increases, the combined effect of more evaporation and sensible heat exchange along with lower initial impervious surface temperature leads to a significant decrease in average predicted runoff temperature, particularly at high impervious percentages.

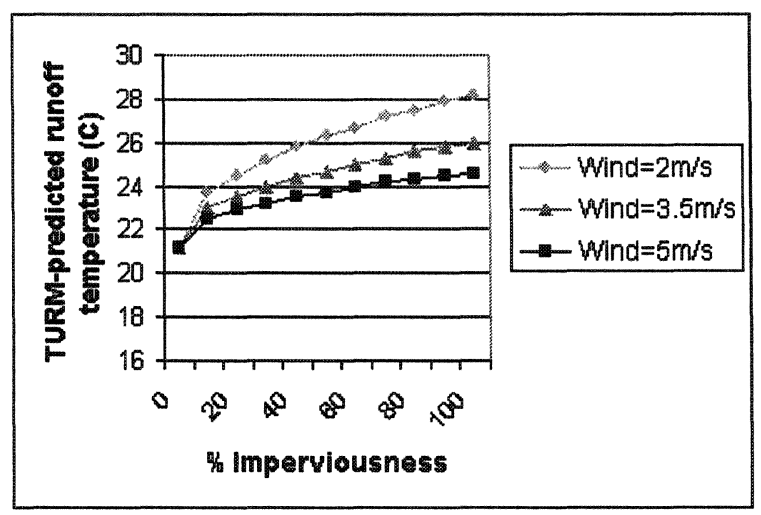

Figure 20.6 Sensitivity of TURM to wind speed during the storm. 
temperatures at lower air temperatures is an indication that TURM-predicted runoff temperatures are sensitive to rain temperature more than they are to air temperature. Although the highest runoff temperatures will generally be measured on the warmest days, this analysis indicates that this is not so much because warm air directly warms water after it begins to run off, but rather that warm air leads to warmer rain, even before that rain contacts the earth's surface.

Figure 20.6 shows that runoff temperatures predicted by TURM are also sensitive to wind speed during the storm. Higher wind speeds allow for more cooling of the heated runoff from impervious surfaces because of increased surface transfer coefficients. Because the pavement surface is warmer than the air, evaporation occurs from this wet surface even though the air is nearly saturated, and a higher transfer coefficient results in more evaporative cooling. Often this rapid evaporation into the nearly saturated air results in condensation or steam fog forming when cool rain falls on hot pavement. A higher transfer coefficient also results in more cooling by sensible heat transfer. Wind speed also affects the initial impervious surface temperature; higher wind speeds cause lower impervious surface temperature because of increased convective heat transfer away from the pavement. Larger changes in initial impervious surface temperature were found over the range of values tested for midday hourly wind speed than for daily solar maximum radiation or maximum air temperature. Thus, when wind speed increases, the combined effect of more evaporation and sensible heat exchange along with lower initial impervious surface temperature leads to a significant decrease in average predicted runoff temperature, particularly at high impervious percentages.

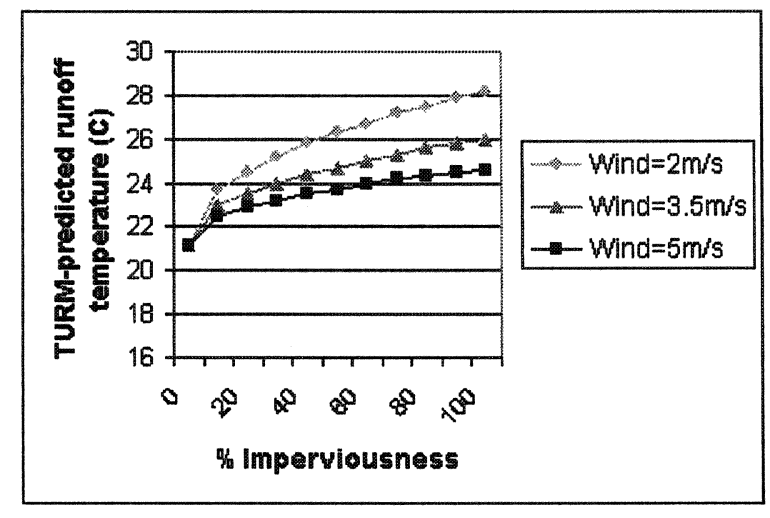

Figure 20.6 Sensitivity of TURM to wind speed during the storm. 


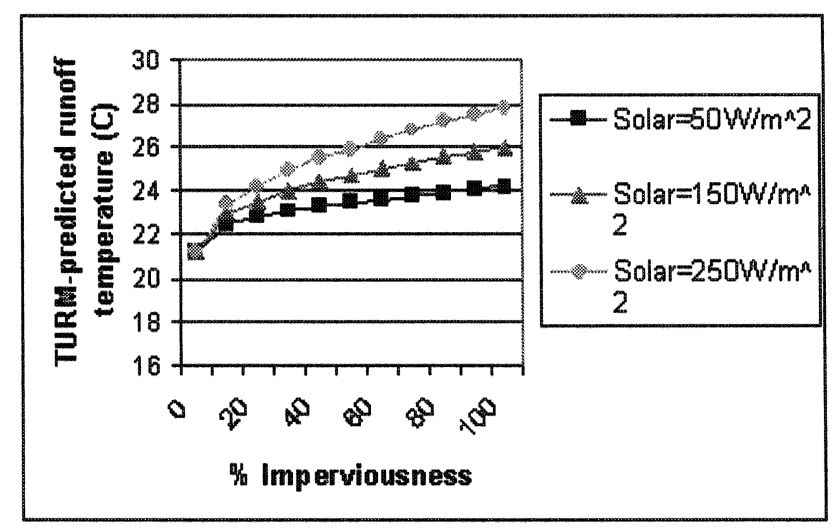

Figure 20.7 Sensitivity of TURM to solar radiation during the storm.

Figure 20.7 shows that TURM is also sensitive to solar radiation during the storm, particularly at high impervious percentages. This is simply because the more energy that runoff from impervious surfaces receives, the more energy it needs to lose through evaporation in order for its temperature to remain constant. If the runoff is not able to lose all this energy through evaporation, its temperature will increase. For the TURM run testing the model's sensitivity to solar radiation during the storm, all conditions affecting the heated runoff's ability to cool through evaporation (relative humidity and wind speed) were held constant. Therefore, higher solar radiation values during the storm resulted in higher predicted runoff temperatures.

The starting hour of the storm only affects initial impervious surface temperature, but this does not have a significant effect on average predicted runoff temperature, as long as the storm occurs near the middle of the day. Nighttime rainfalls could produce considerably lower runoff temperatures because of the likelihood of much cooler impervious surfaces during those hours. (Roa-Espinosa et al., 2003, noted that the lowest runoff temperatures measured in the TURM validation study were during the early morning storm on June 4,2000.) Figure 20.8 shows that TURM is relatively insensitive to the starting hour of the storm over the range of starting hours tested. Although the range of time of maximum air temperatures for Arlington in July was between 1200 and 1600 hours, TURM was run using both 1000 and 1800 hours as the starting times, since this was the time period during which the hourly weather statistics were analyzed. As shown in Figure 20.8, the runoff temperatures predicted by TURM are only slightly lower if the storm is assumed to begin at 1000 or 1800 hours rather than 1400 hours. 


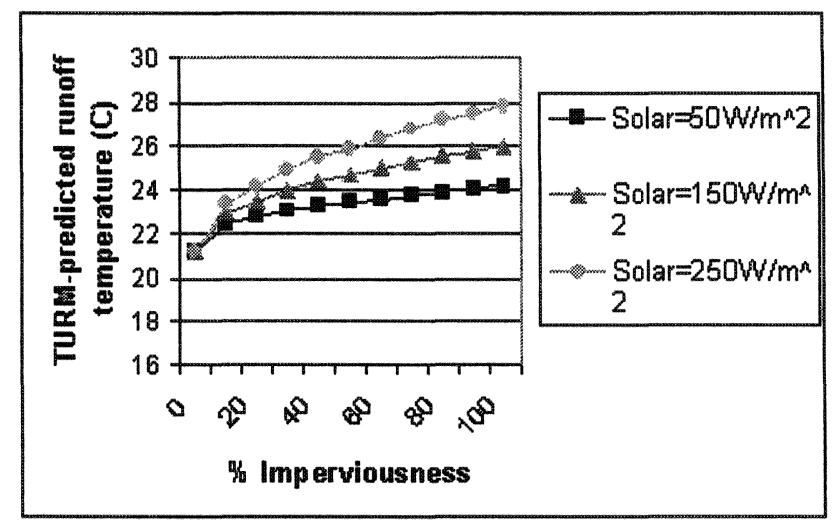

Figure 20.7 Sensitivity of TURM to solar radiation during the storm.

Figure 20.7 shows that TURM is also sensitive to solar radiation during the storm, particularly at high impervious percentages. This is simply because the more energy that runoff from impervious surfaces receives, the more energy it needs to lose through evaporation in order for its temperature to remain constant. If the runoff is not able to lose all this energy through evaporation, its temperature will increase. For the TURM run testing the model's sensitivity to solar radiation during the storm, all conditions affecting the heated runoff's ability to cool through evaporation (relative humidity and wind speed) were held constant. Therefore, higher solar radiation values during the storm resulted in higher predicted runoff temperatures.

The starting hour of the storm only affects initial impervious surface temperature, but this does not have a significant effect on average predicted runoff temperature, as long as the storm occurs near the middle of the day. Nighttime rainfalls could produce considerably lower runoff temperatures because of the likelihood of much cooler impervious surfaces during those hours. (Roa-Espinosa et al., 2003, noted that the lowest runoff temperatures measured in the TURM validation study were during the early morning storm on June 4,2000 .) Figure 20.8 shows that TURM is relatively insensitive to the starting hour of the storm over the range of starting hours tested. Although the range of time of maximum air temperatures for Arlington in July was between 1200 and 1600 hours, TURM was run using both 1000 and 1800 hours as the starting times, since this was the time period during which the hourly weather statistics were analyzed. As shown in Figure 20.8, the runoff temperatures predicted by TURM are only slightly lower if the storm is assumed to begin at 1000 or 1800 hours rather than 1400 hours. 


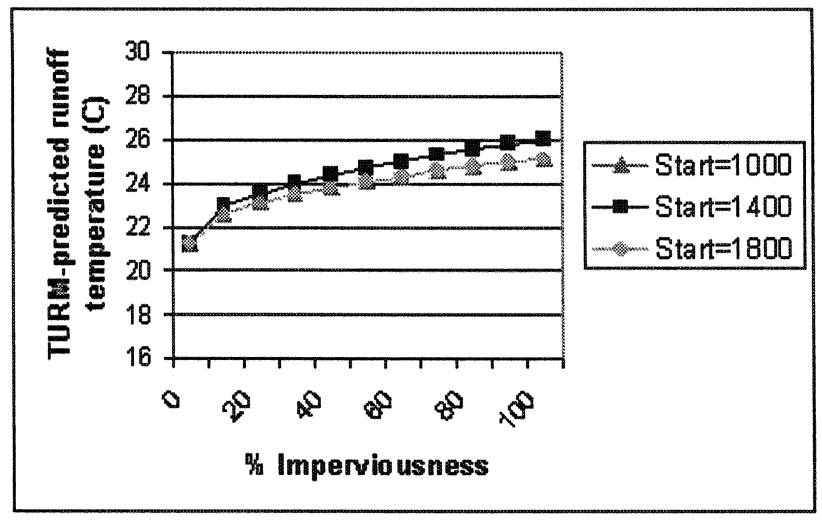

Figure 20.8 Sensitivity of TURM to the starting hour of the storm.

Figure 20.9 shows that slightly greater runoff temperatures are predicted for lower rainfall depths. Figure 20.10 shows that TURM-predicted runoff temperatures are a more sensitive to rainfall duration than rainfall depth, with higher runoff temperatures generated by shorter storms. As discussed previously, these predictions are based on the assumption that runoff depth is a fixed proportion of rainfall depth and that both rainfall and runoff flow rates have constant intensity. Although constant intensity was assumed for each run of TURM, varying the rainfall depth and duration also varied rainfall intensity between TURM runs. In the analysis of TURM's sensitivity to rainfall depth, higher average runoff temperatures were predicted for less intense storms (those with lower rainfall depths). However, in the analysis of TURM's sensitivity to rainfall duration, higher average runoff temperatures were predicted for more intense storms (those with shorter duration). These findings may appear to be in conflict, but in fact they indicate that both timing and intensity determine the average predicted runoff temperature. There is essentially a fixed amount of heat (controlled by the thermal properties of the pavement) that is available to be transferred from pavement to runoff. Higher average runoff temperatures are predicted for lower rainfall depths because the same amount of heat is being transferred to a smaller amount of runoff over a fixed period of time. Higher average runoff temperatures are predicted for shorter storms because most of the heat transfer between pavement and runoff occurs early in the storm; during longer storms, the later runoff from impervious surfaces is significantly cooler, which lowers average predicted runoff temperatures. 


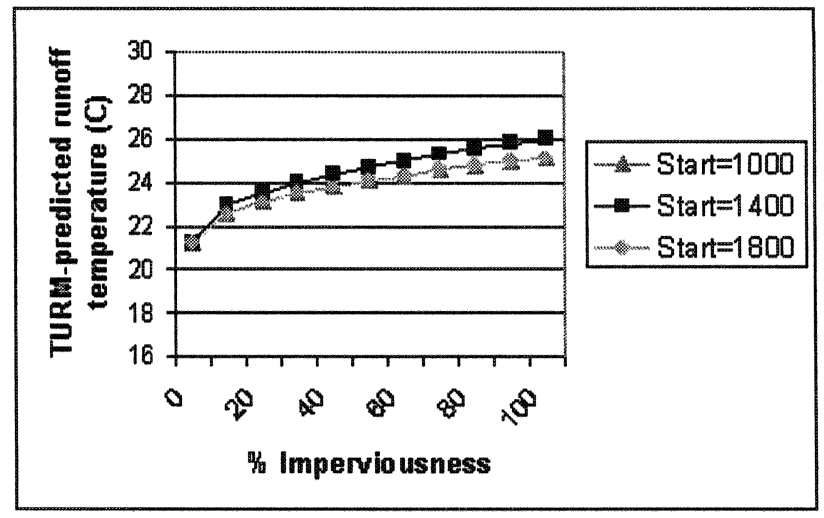

Figure 20.8 Sensitivity of TURM to the starting hour of the storm.

Figure 20.9 shows that slightly greater runoff temperatures are predicted for lower rainfall depths. Figure 20.10 shows that TURM-predicted runoff temperatures are a more sensitive to rainfall duration than rainfall depth, with higher runoff temperatures generated by shorter storms. As discussed previously, these predictions are based on the assumption that runoff depth is a fixed proportion of rainfall depth and that both rainfall and runoff flow rates have constant intensity. Although constant intensity was assumed for each run of TURM, varying the rainfall depth and duration also varied rainfall intensity between TURM runs. In the analysis of TURM's sensitivity to rainfall depth, higher average runoff temperatures were predicted for less intense storms (those with lower rainfall depths). However, in the analysis of TURM's sensitivity to rainfall duration, higher average runoff temperatures were predicted for more intense storms (those with shorter duration). These findings may appear to be in conflict, but in fact they indicate that both timing and intensity determine the average predicted runoff temperature. There is essentially a fixed amount of heat (controlled by the thermal properties of the pavement) that is available to be transferred from pavement to runoff. Higher average runoff temperatures are predicted for lower rainfall depths because the same amount of heat is being transferred to a smaller amount of runoff over a fixed period of time. Higher average runoff temperatures are predicted for shorter storms because most of the heat transfer between pavement and runoff occurs early in the storm; during longer storms, the later runoff from impervious surfaces is significantly cooler, which lowers average predicted runoff temperatures. 


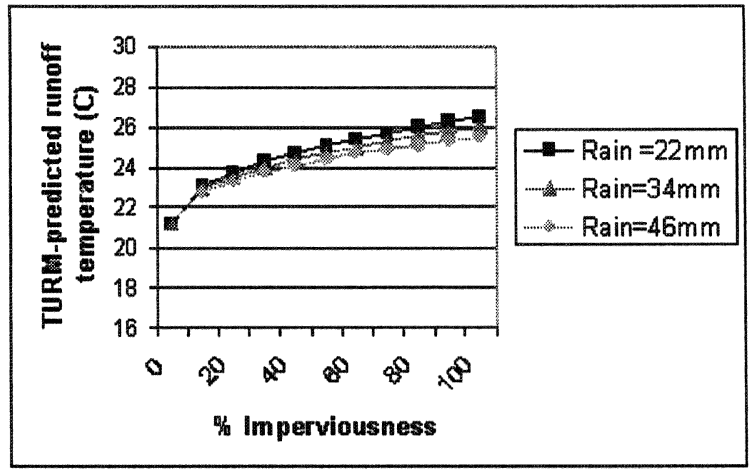

Figure 20.9 Sensitivity of TURM to rainfall depth.

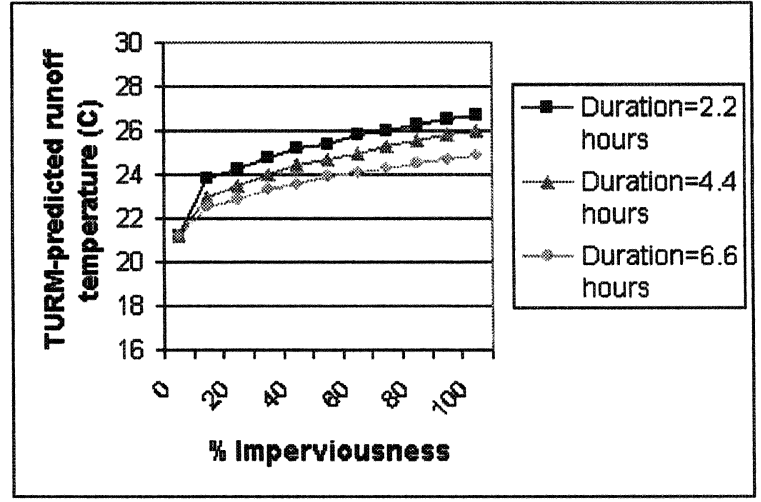

Figure 20.10 Sensitivity of TURM to rainfall duration.

For most of the variables tested in the sensitivity analysis, the relative differences in average predicted runoff temperatures for different values of each variable seem a good indication of the relative thermal impacts of storms that occur under those conditions. However, for rainfall depth, this is not necessarily the case. Although higher average runoff temperatures are predicted for storms with smaller amounts of rainfall, such storms also produce less runoff. The heat content of runoff, which a function of both its volume and its temperature, is the main cause of stream temperature increase resulting from a storm event (Wilson et al., 2004). Therefore, smaller storms might actually have less thermal impact to a stream, even if they produce higher runoff temperatures than larger storms. 


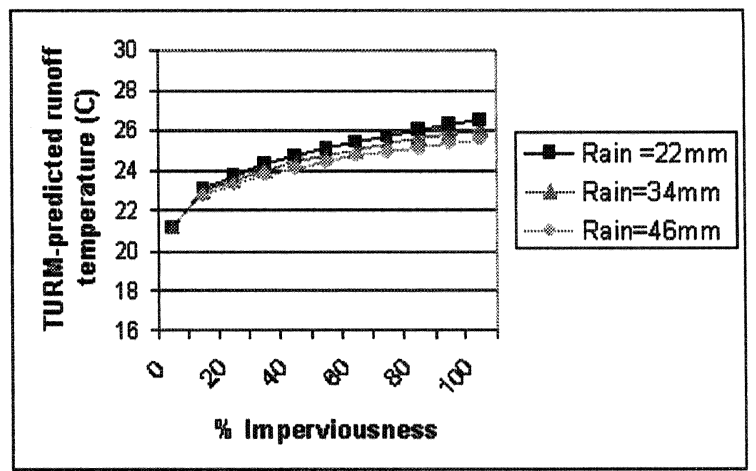

Figure 20.9 Sensitivity of TURM to rainfall depth.

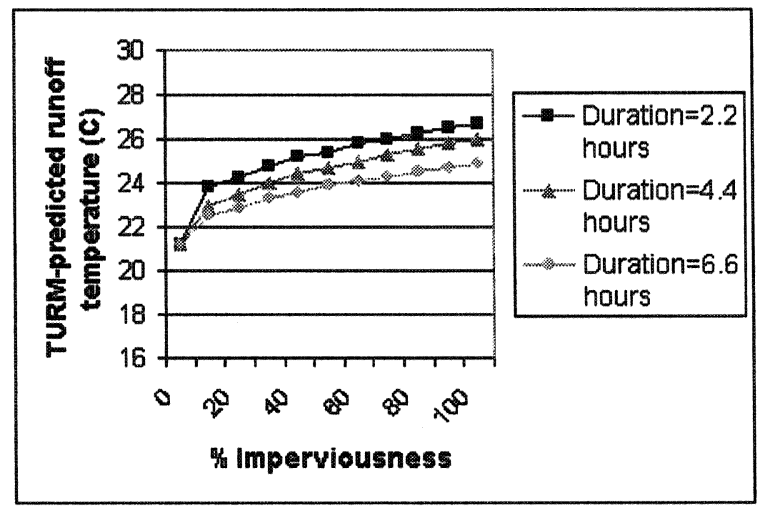

Figure 20.10 Sensitivity of TURM to rainfall duration.

For most of the variables tested in the sensitivity analysis, the relative differences in average predicted runoff temperatures for different values of each variable seem a good indication of the relative thermal impacts of storms that occur under those conditions. However, for rainfall depth, this is not necessarily the case. Although higher average runoff temperatures are predicted for storms with smaller amounts of rainfall, such storms also produce less runoff. The heat content of runoff, which a function of both its volume and its temperature, is the main cause of stream temperature increase resulting from a storm event (Wilson et al., 2004). Therefore, smaller storms might actually have less thermal impact to a stream, even if they produce higher runoff temperatures than larger storms. 
As mentioned in the discussion of TURM's sensitivity to air temperature and relative humidity, TURM is very sensitive to rain (wet bulb) temperature. Figure 20.11 was created by varying wet bulb temperature while holding air temperature constant. This means that as wet bulb temperature increases, relative humidity must increase. Therefore, Figure 20.11 indicates that higher wet bulb temperatures lead to higher predicted runoff temperatures, both because the rain is warmer to begin with and because it is not as able to cool through evaporation at higher relative humidity. Note that the top line in Figure 20.11 reaches higher runoff temperatures than the top line in Figure 20.4 even though the wet bulb temperatures were almost the same in both runs and the air temperature was actually higher for the top line in Figure 20.4. The reason for this difference is that a much higher relative humidity (92\%) was used for the top line in Figure 20.11 than for the top line in Figure 20.4 (50\%).

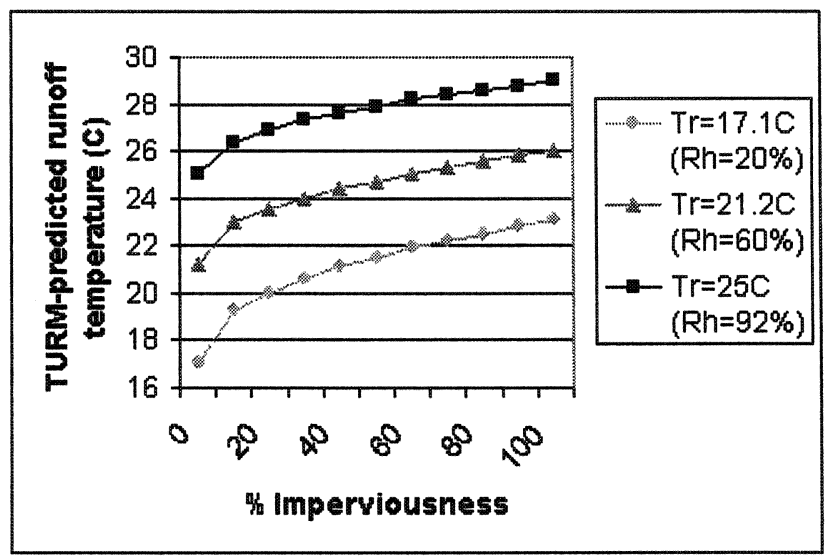

Figure 20.11 Sensitivity of TURM to rain temperature.

Figure 20.12 shows TURM's sensitivity to albedo. The albedo values for this analysis were representative of weathered asphalt $(0.15)$, weathered whitetopping (0.3) and weathered whitetopping with white cement $(0.6)$. These values were determined from the ranges of albedo reported for these surfaces by Bretz et al. (1997). Figure 20.12 indicates that using light colored pavements (higher albedo) in a developed area could provide some reduction in runoff temperature. Increasing albedo has the identical effect to reducing solar radiation so results in Figure 20.12 are similar to Figure 20.3. 
As mentioned in the discussion of TURM's sensitivity to air temperature and relative humidity, TURM is very sensitive to rain (wet bulb) temperature. Figure 20.11 was created by varying wet bulb temperature while holding air temperature constant. This means that as wet bulb temperature increases, relative humidity must increase. Therefore, Figure 20.11 indicates that higher wet bulb temperatures lead to higher predicted runoff temperatures, both because the rain is warmer to begin with and because it is not as able to cool through evaporation at higher relative humidity. Note that the top line in Figure 20.11 reaches higher runoff temperatures than the top line in Figure 20.4 even though the wet bulb temperatures were almost the same in both runs and the air temperature was actually higher for the top line in Figure 20.4. The reason for this difference is that a much higher relative humidity (92\%) was used for the top line in Figure 20.11 than for the top line in Figure 20.4 (50\%).

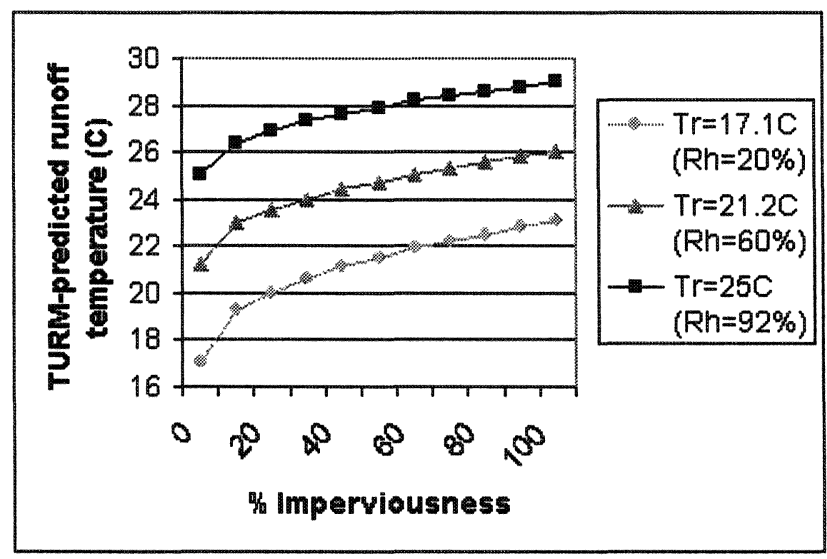

Figure 20.11 Sensitivity of TURM to rain temperature.

Figure 20.12 shows TURM's sensitivity to albedo. The albedo values for this analysis were representative of weathered asphalt $(0.15)$, weathered whitetopping (0.3) and weathered whitetopping with white cement $(0.6)$. These values were determined from the ranges of albedo reported for these surfaces by Bretz et al. (1997). Figure 20.12 indicates that using light colored pavements (higher albedo) in a developed area could provide some reduction in runoff temperature. Increasing albedo has the identical effect to reducing solar radiation so results in Figure 20.12 are similar to Figure 20.3. 


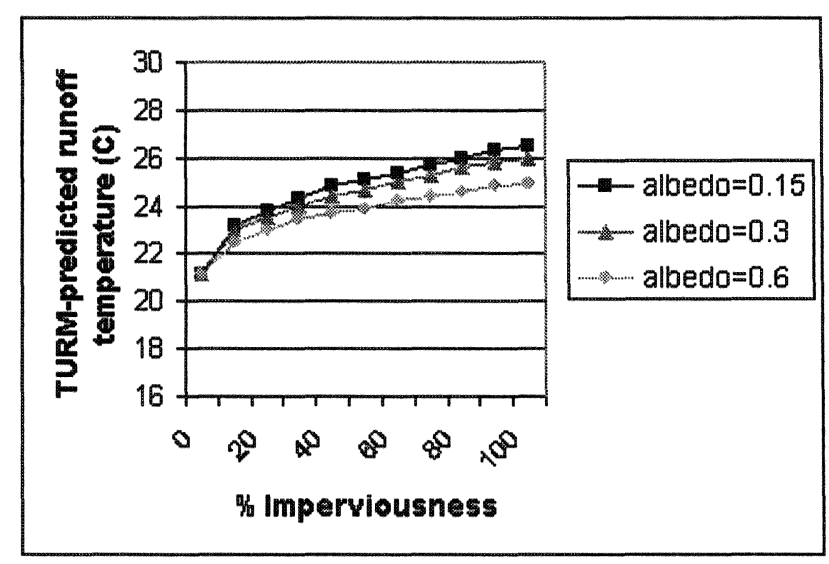

Figure 20.12 Sensitivity of TURM to albedo.

\subsubsection{Review of the Weather Conditions during the Storms in the TURM Validation Study}

Table 20.4 shows a summary of the measured weather variables at Sun Prairie on six days in the summer of 2000 during which storms occurred that were used in the TURM validation study. The Arlington July mean values for these variables are also shown. For some of these weather variables, the Arlington July mean values were within the range (mean plus or minus one standard deviation) of values measured during these selected storms, while for others the Arlington July mean values were clearly outside of the range of the values measured on the days of the selected storms in 2000. The discussion below explains how the weather station statistics, sensitivity analysis and the conditions during the TURM validation study were integrated to select the designstorm value for each variable.

\subsubsection{Selecting Design Storm Values}

The Arlington July mean daily maximum and minimum air temperatures from the weather statistics were within the range of values observed for these variables during the TURM validation storms. Since TURM is not very sensitive to either of these variables, the Arlington July mean values were selected as the design storm values. The Arlington July mean daily maximum solar radiation (from the weather statistics) was slightly outside of the range of values 


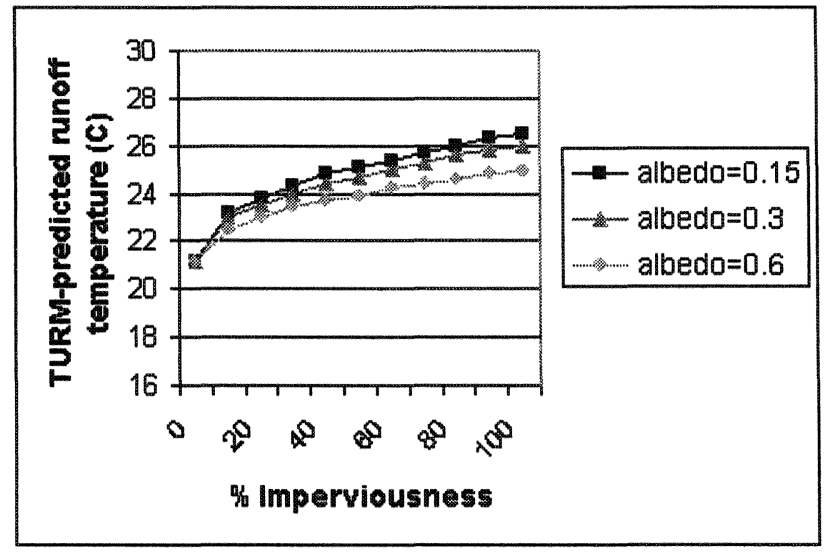

Figure 20.12 Sensitivity of TURM to albedo.

\subsubsection{Review of the Weather Conditions during the Storms in the TURM Validation Study}

Table 20.4 shows a summary of the measured weather variables at Sun Prairie on six days in the summer of 2000 during which storms occurred that were used in the TURM validation study. The Arlington July mean values for these variables are also shown. For some of these weather variables, the Arlington July mean values were within the range (mean plus or minus one standard deviation) of values measured during these selected storms, while for others the Arlington July mean values were clearly outside of the range of the values measured on the days of the selected storms in 2000. The discussion below explains how the weather station statistics, sensitivity analysis and the conditions during the TURM validation study were integrated to select the designstorm value for each variable.

\subsubsection{Selecting Design Storm Values}

The Arlington July mean daily maximum and minimum air temperatures from the weather statistics were within the range of values observed for these variables during the TURMvalidation storms. Since TURM is not very sensitive to either of these variables, the Arlington July mean values were selected as the design storm values. The Arlington July mean daily maximum solar radiation (from the weather statistics) was slightly outside of the range of values 
Table 20.4 Sun Prairie weather statistics for selected 2000 storms.

\begin{tabular}{|c|c|c|c|c|c|c|c|c|c|}
\hline & & \multicolumn{3}{|c|}{ Max Ta Min Ta Max Solar } & $\mathrm{Ta}$ & $\mathrm{Rh}$ & Wind & Solar & Tw \\
\hline Date & Start Hour & $\mathrm{r}(\operatorname{deg} \mathrm{C})$ & $(\operatorname{deg} C)$ & $\left(\mathrm{W} / \mathrm{m}^{\wedge} 2\right)$ & $(\operatorname{deg} C)$ & $(\%)$ & $(\mathrm{m} / \mathrm{s})$ & $\left(\mathrm{W} / \mathrm{m}^{\wedge} 2\right)$ & $(\operatorname{deg} C)$ \\
\hline $6 / 1 / 2000$ & 200 & 29.03 & 15.53 & 722.70 & 15.65 & 93.11 & 0.31 & 0.50 & 15.63 \\
\hline $6 / 1 / 2000$ & 1900 & 29.03 & 15.53 & 722.70 & 27.71 & 69.80 & 1.22 & 1.13 & 18.44 \\
\hline $6 / 4 / 2000$ & 1400 & 12.75 & 10.76 & 154.10 & 12.73 & 86.24 & 0.21 & 44.04 & 11.21 \\
\hline $6 / 13 / 2000$ & 1700 & 21.80 & 13.19 & 673.80 & 21.42 & 81.04 & 0.19 & 5.63 & 18.36 \\
\hline $6 / 20 / 2000$ & 600 & 26.32 & 18.81 & 649.70 & 20.16 & 84.26 & 0.64 & 19.33 & 18.00 \\
\hline $7 / 2 / 2000$ & 2000 & 24.65 & 16.78 & 308.20 & 22.70 & 83.40 & 0.26 & 0.73 & 18.85 \\
\hline $7 / 10 / 2000$ & 500 & 29.03 & 17.65 & 941.70 & 21.11 & 90.50 & 0.25 & 23.66 & 19.76 \\
\hline $8 / 5 / 2000$ & 1200 & 20.88 & 14.37 & 296.10 & 20.88 & 76.68 & 0.92 & 42.01 & 17.38 \\
\hline Mean & & 23.49 & 15.30 & 535.19 & 20.30 & 83.13 & 0.47 & 26.61 & 16.18 \\
\hline Standard De & eviation & 5.71 & 2.77 & 284.80 & 4.50 & 7.45 & 0.48 & 39.92 & 3.16 \\
\hline Arlington $\mathrm{Ju}$ & uly Mean & 27.43 & 14.89 & 967.62 & 25.61 & 58.70 & 3.57 & 158.54 & 19.78 \\
\hline
\end{tabular}

$\mathrm{Max} \mathrm{Ta}=$ Daily maximum air temperature

Min $\mathrm{Ta}=$ Daily minimum air temperature

Max Solar = Daily maximum solar radiation

$\mathrm{Ta}=$ Average air temperature the hour before the storm

$\mathrm{Rh}=$ Average relative humidity the hour before the storm

Wind $=$ Average wind speed the hour before the storm

Solar $=$ Average solar radiation during the storm

$\mathrm{T} w=$ Average wet bulb temperature during the storm

observed for the daily maximum solar radiation during the TURM validation storms. This is most likely due to the fact that the Arlington maximum solar radiation statistics are based only on clear days, while the days of the selected storms were probably not all at least $90 \%$ clear prior to the storm. Since the Arlington July mean value for this variable is the most conservative, this value was selected for the design storm variable value.

The July midday mean air temperature at Arlington was several degrees higher than the average air temperature for the hour before a storm from the Sun Prairie data. Since the sensitivity analysis indicated that TURM was not that sensitive to air temperature alone, a relatively high air temperature would not create a design storm with unreasonably high runoff temperatures. Also, there was one storm studied at Sun Prairie for which the air temperature for the hour before the storm was higher than the July mean midday Arlington temperature. Therefore, the mean July midday Arlington temperature was selected as the value of the air temperature at the beginning of the design storm. 
Table 20.4 Sun Prairie weather statistics for selected 2000 storms.

\begin{tabular}{|c|c|c|c|c|c|c|c|c|c|}
\hline & & \multicolumn{3}{|c|}{ Max Ta Min Ta Max Solar } & $\mathrm{Ta}$ & $\mathrm{Rh}$ & Wind & Solar & Tw \\
\hline Date & Start Hour & $r(\operatorname{deg} C)$ & $(\operatorname{deg} C)$ & $\left(\mathrm{W} / \mathrm{m}^{\wedge} 2\right)$ & $(\operatorname{deg} C)$ & $(\%)$ & $(\mathrm{m} / \mathrm{s})$ & $\left(\mathrm{W} / \mathrm{m}^{\wedge} 2\right)$ & $(\operatorname{deg} C)$ \\
\hline $6 / 1 / 2000$ & 200 & 29.03 & 15.53 & 722.70 & 15.65 & 93.11 & 0.31 & 0.50 & 15.63 \\
\hline $6 / 1 / 2000$ & 1900 & 29.03 & 15.53 & 722.70 & 27.71 & 69.80 & 1.22 & 1.13 & 18.44 \\
\hline $6 / 4 / 2000$ & 1400 & 12.75 & 10.76 & 154.10 & 12.73 & 86.24 & 0.21 & 44.04 & 11.21 \\
\hline $6 / 13 / 2000$ & 1700 & 21.80 & 13.19 & 673.80 & 21.42 & 81.04 & 0.19 & 5.63 & 18.36 \\
\hline $6 / 20 / 2000$ & 600 & 26.32 & 18.81 & 649.70 & 20.16 & 84.26 & 0.64 & 19.33 & 18.00 \\
\hline $7 / 2 / 2000$ & 2000 & 24.65 & 16.78 & 308.20 & 22.70 & 83.40 & 0.26 & 0.73 & 18.85 \\
\hline $7 / 10 / 2000$ & 500 & 29.03 & 17.65 & 941.70 & 21.11 & 90.50 & 0.25 & 23.66 & 19.76 \\
\hline $8 / 5 / 2000$ & 1200 & 20.88 & 14.37 & 296.10 & 20.88 & 76.68 & 0.92 & 42.01 & 17.38 \\
\hline Mean & & 23.49 & 15.30 & 535.19 & 20.30 & 83.13 & 0.47 & 26.61 & 16.18 \\
\hline Standard D & eviation & 5.71 & 2.77 & 284.80 & 4.50 & 7.45 & 0.48 & 39.92 & 3.16 \\
\hline Arlington $\mathrm{J}$ & July Mean & 27.43 & 14.89 & 967.62 & 25.61 & 58.70 & 3.57 & 158.54 & 19.78 \\
\hline
\end{tabular}

$\mathrm{Max} \mathrm{Ta}=$ Daily maximum air temperature

Min $\mathrm{Ta}=$ Daily minimum air temperature

Max Solar $=$ Daily maximum solar radiation

$\mathrm{Ta}=$ Average air temperature the hour before the storm

$\mathrm{Rh}=$ Average relative humidity the hour before the storm

Wind $=$ Average wind speed the hour before the storm

Solar $=$ Average solar radiation during the storm

$\mathrm{Tw}=$ Average wet bulb temperature during the storm

observed for the daily maximum solar radiation during the TURM validation storms. This is most likely due to the fact that the Arlington maximum solar radiation statistics are based only on clear days, while the days of the selected storms were probably not all at least $90 \%$ clear prior to the storm. Since the Arlington July mean value for this variable is the most conservative, this value was selected for the design storm variable value.

The July midday mean air temperature at Arlington was several degrees higher than the average air temperature for the hour before a storm from the Sun Prairie data. Since the sensitivity analysis indicated that TURM was not that sensitive to air temperature alone, a relatively high air temperature would not create a design storm with unreasonably high runoff temperatures. Also, there was one storm studied at Sun Prairie for which the air temperature for the hour before the storm was higher than the July mean midday Arlington temperature. Therefore, the mean July midday Arlington temperature was selected as the value of the air temperature at the beginning of the design storm. 
The mean July midday relative humidity at Arlington was considerably lower than the relative humidity for the hour before most of the storms at Sun Prairie. The sensitivity analysis revealed that TURM is somewhat sensitive to relative humidity, but not nearly as sensitive as it is to rain temperature. Therefore, the selection of an appropriate design-storm wet bulb value was more important than the selection of an appropriate design-storm relative humidity value. Thus the design-storm values for air and rain temperature were selected first and then the corresponding relative humidity was calculated (discussed later under rain temperature).

Wind speed during the storm was a variable to which TURM was very sensitive. Although there were some statistically significant differences found between the midday wind speeds for the three weather stations, overall the midday wind speeds at these stations were reasonably similar compared to the much lower measured wind speeds at Sun Prairie during the 2000 storms (Arrington, 2003). In order to confirm that wind speed was consistently lower at Sun Prairie than at Arlington, ratios of the wind speeds between the two stations were taken for every midday hour during which a measurement for the same height at both stations was available (late May through mid July 2000). The average of the ratio of Sun Prairie to Arlington wind speed was 0.25 (with a standard deviation of 0.14 ), indicating that Sun Prairie experiences consistently lower wind speeds than Arlington.

This difference is most likely due to the fact that the Arlington weather station is in a relatively rural area, while the Sun Prairie weather station is in a more urban area. The presence of buildings and trees in urban areas creates a rough surface for wind to travel through, producing friction that reduces wind speed. (The trees were taller than the houses in the two subdivisions were the TURM validation study was performed.) Roughness length is a property of a surface (such as a farm field or and urban area) that is a measure of the friction in the layer of air that interacts with that surface (Campbell and Norman, 1998). At a given height above different surfaces, lower wind speeds can be expected for surfaces with greater values for roughness length. Hansen (1993) gives empirically determined values for the roughness lengths of several surfaces, including alfalfa $(3 \mathrm{~cm})$, potatoes $(4 \mathrm{~cm})$, low-density residential areas $(110 \mathrm{~cm})$ and urban areas $(175-320 \mathrm{~cm})$. These numbers suggest that, at a given measurement height that is relatively close to the ground (such as $3 \mathrm{~m}$ for the Arlington and Sun Prairie stations), urban areas generally experience lower wind speeds than open agricultural fields.

The average ratio of the wind speeds for 2000 at Arlington and Sun Prairie (0.25) was multiplied by the mean July midday wind speed at Arlington to 
The mean July midday relative humidity at Arlington was considerably lower than the relative humidity for the hour before most of the storms at Sun Prairie. The sensitivity analysis revealed that TURM is somewhat sensitive to relative humidity, but not nearly as sensitive as it is to rain temperature. Therefore, the selection of an appropriate design-storm wet bulb value was more important than the selection of an appropriate design-storm relative humidity value. Thus the design-storm values for air and rain temperature were selected first and then the corresponding relative humidity was calculated (discussed later under rain temperature).

Wind speed during the storm was a variable to which TURM was very sensitive. Although there were some statistically significant differences found between the midday wind speeds for the three weather stations, overall the midday wind speeds at these stations were reasonably similar compared to the much lower measured wind speeds at Sun Prairie during the 2000 storms (Arrington, 2003). In order to confirm that wind speed was consistently lower at Sun Prairie than at Arlington, ratios of the wind speeds between the two stations were taken for every midday hour during which a measurement for the same height at both stations was available (late May through mid July 2000). The average of the ratio of Sun Prairie to Arlington wind speed was 0.25 (with a standard deviation of 0.14 ), indicating that Sun Prairie experiences consistently lower wind speeds than Arlington.

This difference is most likely due to the fact that the Arlington weather station is in a relatively rural area, while the Sun Prairie weather station is in a more urban area. The presence of buildings and trees in urban areas creates a rough surface for wind to travel through, producing friction that reduces wind speed. (The trees were taller than the houses in the two subdivisions were the TURM validation study was performed.) Roughness length is a property of a surface (such as a farm field or and urban area) that is a measure of the friction in the layer of air that interacts with that surface (Campbell and Norman, 1998). At a given height above different surfaces, lower wind speeds can be expected for surfaces with greater values for roughness length. Hansen (1993) gives empirically determined values for the roughness lengths of several surfaces, including alfalfa $(3 \mathrm{~cm})$, potatoes $(4 \mathrm{~cm})$, low-density residential areas $(110 \mathrm{~cm})$ and urban areas $(175-320 \mathrm{~cm})$. These numbers suggest that, at a given measurement height that is relatively close to the ground (such as $3 \mathrm{~m}$ for the Arlington and Sun Prairie stations), urban areas generally experience lower wind speeds than open agricultural fields.

The average ratio of the wind speeds for 2000 at Arlington and Sun Prairie (0.25) was multiplied by the mean July midday wind speed at Arlington to 
determine the design storm wind speed. This is a much more conservative value for wind speed than the mean Arlington July midday value because as shown in Figure 20.6, TURM predicts higher runoff temperatures for lower wind speeds. Still, the assumption that all areas experience wind speeds that are more typical of an urban area when selecting design storm values is not unreasonable even if it leads to an overprediction of thermal impact for development projects in more rural areas. If Arlington-like wind speeds were used for the design storm, significant underprediction of thermal impact of development projects in urban areas could result.

Table 20.4 shows that the Arlington July mean midday solar radiation was much higher than the mean solar radiation during the selected storm hours at Sun Prairie. (The statistics for both of these weather stations are based on hourly average solar radiation measurements.) Unlike with wind speed, Sun Prairie does not consistently experience lower solar radiation than Arlington (Arrington, 2003). Part of the reason for the differences in solar radiation shown in Table 20.4 is that not all of the selected storms occurred during the midday hours and that these storms took place in June, July and August, while the Arlington value for solar radiation in Table 20.4 is based on July midday hours with precipitation. Also, solar radiation during storms is highly variable, even among storms that occur during the midday hours. This is evident from the high standard deviation of $168 \mathrm{~W} / \mathrm{m}^{2}$ for Arlington solar radiation during July midday hours with precipitation (which is based on $17 \mathrm{y}$ of weather records). The storms in the TURM validation study might not have been a sufficient sample size to capture the range of variability in solar radiation during midday hours with precipitation (especially since only three of these storms began during the midday hours). Since TURM is sensitive to solar radiation during the storm and the Arlington mean July solar radiation value during midday hours with precipitation $\left(160 \mathrm{~W} / \mathrm{m}^{2}\right)$ was more conservative than the solar radiation measured during the Sun Prairie storms, the Arlington value was selected as the value for solar radiation during the design storm.

As mentioned previously, the starting hour of the storm was selected from the time of maximum air temperatures. Figure 20.1 shows that the average time of maximum air temperature is approximately at 1400 hours during the summer months. The sine curve used to approximate impervious surface temperature also predicts that the maximum temperature of impervious surfaces occurs at 1400 hours. The sensitivity analysis revealed that TURM is not very sensitive to the starting hour of the storm as long as it begins sometime within the midday hours. Therefore, the design storm was chosen to begin at 1400 hours. 
determine the design storm wind speed. This is a much more conservative value for wind speed than the mean Arlington July midday value because as shown in Figure 20.6, TURM predicts higher runoff temperatures for lower wind speeds. Still, the assumption that all areas experience wind speeds that are more typical of an urban area when selecting design storm values is not unreasonable even if it leads to an overprediction of thermal impact for development projects in more rural areas. If Arlington-like wind speeds were used for the design storm, significant underprediction of thermal impact of development projects in urban areas could result.

Table 20.4 shows that the Arlington July mean midday solar radiation was much higher than the mean solar radiation during the selected storm hours at Sun Prairie. (The statistics for both of these weather stations are based on hourly average solar radiation measurements.) Unlike with wind speed, Sun Prairie does not consistently experience lower solar radiation than Arlington (Arrington, 2003). Part of the reason for the differences in solar radiation shown in Table 20.4 is that not all of the selected storms occurred during the midday hours and that these storms took place in June, July and August, while the Arlington value for solar radiation in Table 20.4 is based on July midday hours with precipitation. Also, solar radiation during storms is highly variable, even among storms that occur during the midday hours. This is evident from the high standard deviation of $168 \mathrm{~W} / \mathrm{m}^{2}$ for Arlington solar radiation during July midday hours with precipitation (which is based on $17 \mathrm{y}$ of weather records). The storms in the TURM validation study might not have been a sufficient sample size to capture the range of variability in solar radiation during midday hours with precipitation (especially since only three of these storms began during the midday hours). Since TURM is sensitive to solar radiation during the storm and the Arlington mean July solar radiation value during midday hours with precipitation $\left(160 \mathrm{~W} / \mathrm{m}^{2}\right)$ was more conservative than the solar radiation measured during the Sun Prairie storms, the Arlington value was selected as the value for solar radiation during the design storm.

As mentioned previously, the starting hour of the storm was selected from the time of maximum air temperatures. Figure 20.1 shows that the average time of maximum air temperature is approximately at 1400 hours during the summer months. The sine curve used to approximate impervious surface temperature also predicts that the maximum temperature of impervious surfaces occurs at 1400 hours. The sensitivity analysis revealed that TURM is not very sensitive to the starting hour of the storm as long as it begins sometime within the midday hours. Therefore, the design storm was chosen to begin at 1400 hours. 
The average rainfall depth and duration from the validation study $(33 \mathrm{~mm}$ in $4.4 \mathrm{~h}$ ) were selected for the design storm for TURM. A storm of this size is large enough to produce a significant amount of runoff, yet small enough that the high-temperature runoff produced early in the storm is still likely to have an important effect on stream temperature. Although higher runoff temperatures would be predicted for smaller storms (as shown in the sensitivity analysis), smaller storms would also produce less runoff, so they would not necessarily have a significant thermal impact potential. Larger storms would produce more runoff, but cooler runoff produced later during larger storms is likely to significantly reduce the average runoff temperature over the storm's duration. (Since there is only a finite amount of heat that can be transferred from an area of pavement to runoff, once most of that heat has been transferred, additional rain only mitigates the thermal impact of the early, high-temperature runoff.)

The rain temperature was the final design storm variable value to select. The sensitivity analysis indicated that TURM is very sensitive to this variable. The statistical analyses (Arrington, 2003) showed that there are some significant differences in the midday wet bulb temperatures between the three weather stations, particularly between Arlington and West Madison (1992-1997). Of the three weather stations, the wet bulb temperatures were generally highest at Arlington. Table 20.4 indicates that the mean July Arlington wet bulb temperature (1985-2002) is approximately equal to the mean wet bulb temperature plus one standard deviation of the selected 2000 storms. Thus the mean July Arlington wet bulb temperature is a conservative rain temperature, but since TURM is quite sensitive to the value of this variable, its design-storm value should be conservative.

Table 20.5 shows a summary of the selected design storm parameter values for TURM in Dane County.

Currently, the assumed albedo used in TURM is 0.3 , which is an intermediate value between that of asphalt and white cement. In the future, the model could be adapted to compute runoff temperatures separately from different types of surfaces, and demonstrate the effect of replacing darkcolored impervious surfaces with light-colored ones on the thermal impact of a particular development project.

\subsection{Conclusions}

Over the long term, the implementation of this section of the new ordinance can be considered successful if the streams that it was designed to protect remain healthy cold water communities, despite the increases in development that are 
The average rainfall depth and duration from the validation study $(33 \mathrm{~mm}$ in $4.4 \mathrm{~h}$ ) were selected for the design storm for TURM. A storm of this size is large enough to produce a significant amount of runoff, yet small enough that the high-temperature runoff produced early in the storm is still likely to have an important effect on stream temperature. Although higher runoff temperatures would be predicted for smaller storms (as shown in the sensitivity analysis), smaller storms would also produce less runoff, so they would not necessarily have a significant thermal impact potential. Larger storms would produce more runoff, but cooler runoff produced later during larger storms is likely to significantly reduce the average runoff temperature over the storm's duration. (Since there is only a finite amount of heat that can be transferred from an area of pavement to runoff, once most of that heat has been transferred, additional rain only mitigates the thermal impact of the early, high-temperature runoff.)

The rain temperature was the final design storm variable value to select. The sensitivity analysis indicated that TURM is very sensitive to this variable. The statistical analyses (Arrington, 2003) showed that there are some significant differences in the midday wet bulb temperatures between the three weather stations, particularly between Arlington and West Madison (1992-1997). Of the three weather stations, the wet bulb temperatures were generally highest at Arlington. Table 20.4 indicates that the mean July Arlington wet bulb temperature (1985-2002) is approximately equal to the mean wet bulb temperature plus one standard deviation of the selected 2000 storms. Thus the mean July Arlington wet bulb temperature is a conservative rain temperature, but since TURM is quite sensitive to the value of this variable, its design-storm value should be conservative.

Table 20.5 shows a summary of the selected design storm parameter values for TURM in Dane County.

Currently, the assumed albedo used in TURM is 0.3 , which is an intermediate value between that of asphalt and white cement. In the future, the model could be adapted to compute runoff temperatures separately from different types of surfaces, and demonstrate the effect of replacing darkcolored impervious surfaces with light-colored ones on the thermal impact of a particular development project.

\subsection{Conclusions}

Over the long term, the implementation of this section of the new ordinance can be considered successful if the streams that it was designed to protect remain healthy cold water communities, despite the increases in development that are 
Table 20.5 Summary of weather variable values selected for the design storm.

\begin{tabular}{lc}
\hline Weather Variable & Design Storm Value \\
\hline Maximum daily air temperature - C & 27.4 \\
Minimum daily air temperature - C & 15.0 \\
Maximum daily solar radiation - W/m^2 & 970 \\
Air temperature just prior to the storm - C & 25.6 \\
Relative humidity just prior to the storm - \% & 58.7 \\
Wind speed during the storm - m/s & 0.9 \\
Solar radiation during the storm- W/m^2 & 160 \\
Hour that the storm begins & 14 \\
Rainfall depth - mm & 33 \\
Rainfall duration - hours & 4.4 \\
Rain temperature - C & 19.8 \\
\hline
\end{tabular}

likely to occur in these watersheds. This means both that thermal impact assessments must be accurate and that temperature reduction practices must be effectively designed and implemented so as prevent stream temperature increases from reaching unacceptably high levels for a cold water community.

The first step toward being able to accurately assess thermal impact was the development and validation of TURM (Roa-Espinosa et al., 2003; Wilson et al., 2004). TURM has been shown to predict runoff temperatures from developed parcels with reasonable accuracy for planning purposes (within 2.5(C), which is a good sign that the model is capturing the important factors in determining how heat is transferred between impervious surfaces and precipitation during a storm event. Another step toward the successful implementation of the thermal impact component was the selection of the design storm values. Fixing the values of these weather variables in versions of TURM that are released to the public will ensure both uniformity among users and reasonableness of the values for a storm with a high thermal impact potential, thereby moving TURM from being a validated model (Roa-Espinosa et al., 2003; Wilson et al., 2004) to being a predictive tool. However, the specific design storm values are by no means permanent and should be closely scrutinized to determine if they are reasonable to use for thermal impact assessments. This will be done after further testing of TURM and as people become more experienced with using the model as a predictive tool. The sensitivity analysis of TURM to the weather variables it requires should be a useful guide in making changes to the design storm values. 
Table 20.5 Summary of weather variable values selected for the design storm.

\begin{tabular}{lc}
\hline Weather Variable & Design Storm Value \\
\hline Maximum daily air temperature - C & 27.4 \\
Minimum daily air temperature - C & 15.0 \\
Maximum daily solar radiation - W/m^2 & 970 \\
Air temperature just prior to the storm - C & 25.6 \\
Relative humidity just prior to the storm - \% & 58.7 \\
Wind speed during the storm - $\mathrm{m} / \mathrm{s}$ & 0.9 \\
Solar radiation during the storm- W/m^2 & 160 \\
Hour that the storm begins & 14 \\
Rainfall depth - mm & 33 \\
Rainfall duration - hours & 4.4 \\
Rain temperature - C & 19.8 \\
\hline
\end{tabular}

likely to occur in these watersheds. This means both that thermal impact assessments must be accurate and that temperature reduction practices must be effectively designed and implemented so as prevent stream temperature increases from reaching unacceptably high levels for a cold water community.

The first step toward being able to accurately assess thermal impact was the development and validation of TURM (Roa-Espinosa et al., 2003; Wilson et al., 2004). TURM has been shown to predict runoff temperatures from developed parcels with reasonable accuracy for planning purposes (within 2.5(C), which is a good sign that the model is capturing the important factors in determining how heat is transferred between impervious surfaces and precipitation during a storm event. Another step toward the successful implementation of the thermal impact component was the selection of the design storm values. Fixing the values of these weather variables in versions of TURM that are released to the public will ensure both uniformity among users and reasonableness of the values for a storm with a high thermal impact potential, thereby moving TURM from being a validated model (Roa-Espinosa et al., 2003; Wilson et al., 2004) to being a predictive tool. However, the specific design storm values are by no means permanent and should be closely scrutinized to determine if they are reasonable to use for thermal impact assessments. This will be done after further testing of TURM and as people become more experienced with using the model as a predictive tool. The sensitivity analysis of TURM to the weather variables it requires should be a useful guide in making changes to the design storm values. 
More work is needed before the thermal control section of the ordinance is successfully implemented. TURM currently includes equations for predicting both runoff resulting from a development project, and the model has been validated for predicting runoff temperatures (Roa-Espinosa et al., 2003; Wilson et al., 2004). However, predicting temperature changes as heated runoff travels from a developed parcel to a cold water stream remains to be done because the current stream temperature prediction equations assume no change in runoff temperature during this journey. Fortunately the temperatures of cold-water streams are generally known so that accurate stream temperature predictions are not necessary. The strength of TURM is that given stream flow and temperature, it provides estimates of increases in stream temperature from future development - this temperature increase is the quantity of interest for preserving stream integrity.

Finally, although the ordinance focuses on the thermal impact of individual parcels, the true thermal impact of development on a cold water stream is the result of runoff temperature increases by many parcels draining to that stream. Even if the ordinance reduces the thermal impact of many development projects in a cold water watershed, the cumulative impact of these projects might still result in a periodic stream temperature increases with the potential to be very damaging to a cold water community. Therefore, efforts must be made to move thermal impact assessments to the watershed scale in order to ensure the protection of cold water streams. The watershed-scale thermal impact assessments should be valuable for three reasons. First, they will further examine TURM's validity at the watershed scale. Second, they will provide further understanding about the temperature reductions necessary at the parcel level to maintain the integrity of a particular cold water stream. Finally, these assessments will be useful guides for planning and zoning decisions regarding how much additional development a particular cold water watershed can support without severely degrading that stream.

\section{References}

Arrington, K.E. 2003. Tools to support the protection of cold water streams from the thermal impact of development in Dane County, Wisconsin. M.S. thesis. University of Wisconsin-Madison.

Arrington, K.E., S.J. Ventura, J.M. Norman and A. Roa-Espinosa. 2003. Protecting cold water streams in urbanizing watersheds. Journal of soil and water conservation 58:62-65. 
Bretz, S., H. Akbari, and A. Rosenfeld. 1998. Practical issues for using solar-reflective materials to mitigate urban heat islands. Atmospheric Environment 32:95-101.

Campbell, G.S. and J.M. Norman. 1998. An introduction to environmental biophysics. Springer, New York.

Dane County Board. 2001. Dane County Code of Ordinances, Chapter 14, Ord. Amend. No.2, 2001-02.

Galli, J. 1990.Thermal impacts associated with urbanization and stormwater best management practices. Department of Environmental Programs, Metropolitan Washington Council of Governments, Washington, DC.

Hansen, F.V. 1993. Surface roughness lengths. ARL Technical Report. U.S. Army, White Sands Missile Range, NM.

Johnson, K. 1995. Urban stormwater impacts on a coldwater resource. Kiap-TU-Wish Chapter, Trout Unlimited, Hudson-River Falls, WI. (Available online at http:// www.lambcom.net/kiaptuwish/stormwater/title.html) (accessed 21 June 2002; verified 10 January 2003).

Klein, R.D. 1979. Urbanization and stream quality impairment. Water Resour. Bull. 15:948-960.

LeBlanc, R.T., R.D. Brown, and J.E. FitzGibbon. 1996. Modeling the effects of land use change on the water temperature in unregulated streams. J. Environ. Management 49:445-469.

Pitt, R. 1991. Detention pond design for water quality. In Designing storm water quality management practices. University of Wisconsin Department of Professional Development, Madison, WI.

Pluhowski, E.J. 1970. Urbanization and its effect on the temperature of the streams in Long Island, New York. United States Geological Survey, Professional Paper 627-D. United States Geological Survey, Washington, DC.

Roa-Espinosa, A., J.M. Norman, T.B. Wilson, and K. Johnson. 2003. Predicting the impact of urban development on stream temperature using a Thermal Urban Runoff Model (TURM). p.369-389. In Proc. National Conference on Urban Stormwater: Enhancing Programs at the Local Level, Chicago, IL, 17-20 Feb. 2003. U.S. EPA, National Risk Management Research Laboratory, Cincinnati, $\mathrm{OH}$.

Roesner, L.E. H.J. Burgess, and J.A. Aldrich. 1991. The hydrology of urban runoff quality management. Water Resources Planning and Management and Urban Water Resources. Proceedings of ASCE Special Conference. ASCE, New York.

United States Army Corps of Engineers. 1956. Snow Hydrology. United States Army Corps of Engineers, Portland.

United States Department of Agriculture-Soil Conservation Service. 1986. Urban hydrology for small watersheds. Technical Release 55.

United States Department of Commerce, Bureau of the Census. 2003. 2000 Census of Population and Housing, Population and Housing Unit Counts PHC-3-51, Wisconsin. Washington, D.C.

Wilson, T.B., J.M. Norman, A. Roa-Espinosa, and S. Greb. 2004. Modeling the effect of summertime heating on urban runoff temperature. Water Resource Research, 
In Review.

Wisconsin Department of Natural Resources. 1997. Chapter NR 102: Water Quality Standards for Wisconsin Surface Waters. In Wisconsin Administrative Code. 